$$
\text { KFKI-1981-78 }
$$

I. VINCZE

FOURIER EVALUATION OF BROAD MÖSSBAUER SPECTRA

Hungarian Academy of Sciences

CENTRAL

RESEARCH

INSTITUTE FOR

PHYSICS 
$$
2 n 17
$$ 


\section{FOURIER EVALUATION OF BROAD MÖSSBAUER SPECTRA}

\section{Vincze}

\section{Solid State Physics Laboratory Materials Science Center, University of Groningen \\ 9718 EP Groningen, The Netherlands}

HU ISSN 03685330

ISBN $963 \quad 371 \quad 860 \quad 0$

on leave from: Central Research Institute for Physics, Budapest, P.0.Box 49 Hungary, 1525 


\section{ABSTRACT}

It is shown by the Fourier analysis of broad Mössbauer spectra that the even part of the distribution of the dominant hyperfine interaction /hyperfine field or quadrupole splitting/ can be obtained directly without using least-square fitting procedures. Also the odd part of this distribution correlated with other hyperfine parameters /e.g. isomer shift/ can be directly determined. Examples covering the case of amorphous magnetic and paramagnetic iron-based alloys are presented.

\section{АННОТАЦИЯ}

Анализом Фурье широких спектров Мессбауэра показано, что четную часть распределения доминирующих сверхтонких взаимодействий/расщепление сверхтонкого поля или квадрупольное расщепление/ можно получить непосредственно, без подгонки методом наименыших квадратов. Нечетную часть этого же распределения при коррелировании с другими сверхтонкими параметрами /например, с изомерным сдвигом/ также можно определить непосредственно. Приведены примеры для случаев аморфных магнитных и парамагнитных сплавов на основе железа.

\section{KIVONAT}

Megmutatjuk a széles Mössbauer spektrumok Fourier analizisével, hogỳ a domináns hiperfinom kölcsönhatás /hiperfinom tér vagy kvadrupol felhasadás/ eloszlásának páros részét direkt módon meg lehet kapni, legkisebb négyzetes fittelési eljárás nélkự. Ennek az eloszlásnak a páratlan része más hiperfinom paraméterekkel korrelálva /pl. izomer eltolódás / szintén direkt módon meghatározható. Amorf mágneses és paramágneses vas-alapu ötvözetek példáit mutatjuk be. 


\section{Introduction}

Disordered systems often exhibit broad Mössbauer spectra due to the fluctuation in the strength of the hyperfine interactions from site to site. These spectra can be described by the distributions of the hyperfine parameters (hyperfine field $H$, quadrupole splitting $\Delta E_{Q}$ and isomer shift IS). The evaluation of these distributions from the measured spectrum is a difficult task and many different approaches have been proposed.

The most widely used methods assume that one type of hyperfine interaction is dominant (e.g. hyperfine field) and the distribution function is expanded in terms of trigonometric functions [1] or stepfunctions [2]. The coefficients of this series are determined from a least-square fitting procedure of the spectrum. Improvements and difficulties of these methods are discussed in Refs. [3] and [4].

The common feature and basic problem of all published evaluation methods lays in the use of a least-square fitting procedure to determine the parameters characteristic of the distribution. The number of parameters necessary to obtain a reliable fit of the spectra is a sensitive function of the chosen approach. It is difficult to find the optimum solution with the possible smallest number of parameters. This can be illustrated with the example of amorphous ferromagnetic alloys where generally about 9-12 parameters (cosine components) are necessary to determine the shape of the hyperfine field distribution with Window's method [1]. The same accuracy (1.e. $\chi^{2}$-value) can be reached by using only 3-5 parameters when the binomial distribution method (BD) $[5]$ is used.

In the following the application of Fourier analysis to the evaluation of these distributions will be discussed. It will be shown that the even part of the distribution of the dominant hyperfine interaction and the odd part of this distribution correlated with other hyperfine interactions can be directly determined in the case of broad distributions - without the use of least-square fitting procedures. The results on amorphous iron-based alloys obtained via this method will be compared with those of the BD method on the same systems. Fourier transformation has been used earlier for the removal of sample thickness effects 
In the Mössbauer spectra [6] and to Increase the resolution of the Mössbauer spectra $[7]$.

\section{Basic equations}

We will assume for the sake of simplicity (but without loosing generality) that the distribution of hyperfine parameters are given by $p(h, s)$, where $h$ stands for hyperfine field or quadrupole splitting (according to the actual specification) and $\mathrm{S}$ is the isomer shift (or a combination of isomer shift and quadrupole splitting, according to the specification). p(h,S) is normalized, i.e.

$$
\iint \mathbf{p}(\mathbf{h}, \mathbf{S}) \mathrm{dhdS}=1
$$

where the integrals are taken between $-\infty$ and $+\infty$ (as always through this work when no other boundaries are given).

The Mössbauer spectrum with this probability distribution after the substraction of the background is given as

$$
S(v)=\iint p(h, S) L(h, s, v) \text { dhds, }
$$

where $v$ is the relative velocity between source and absorber, ana

$$
L(h, s, v)=\frac{1}{1+\left(\frac{v-h+s}{G}\right)^{2}}+\frac{1}{1+\left(\frac{v+h+s}{G}\right)^{2}} .
$$

Here $G$ is the half-linewidth of the individual Lorentzian components and it will be assumed that all elementary components have the same width, 1.e. G is not distributed (that is no sample thickness effects will be considered). The Mössbauer spectrum given in Eq. (3) corresponds to the elementary spectrum of paramagnetic ${ }^{57} \mathrm{Fe}(3 / 2-1 / 2$ transition) where $\mathrm{h}=$ $\Delta E_{Q} / 2=Q$ and $S=I S$ or it represents one doublet of the six-1ine pattern of a magnetically split ${ }^{57}$ Fe elementary spectrum when $h$ is proportional to the hyperfine field $H$ (via the proper g-factor combination) and $S$ is a combination of quadrupole and isomer shifts. Eq. (3) should be replaced with the proper expression when the method is used for other nuclear transitions.

The Fourier transformed $S(v)$ is defined as 


$$
s(k)=\int s(v) e^{i k v} d v
$$

which reduces into

$$
s(k)=\left(\iint p(h, S) 2 \cos (k h) e^{-i k S} d h d S\right)\left(\pi G e^{-G|k|}\right) .
$$

The definition of $s(k)$ deconvoluted from the Lorentzian contribution is

$$
\mathbf{s}_{D C}(\mathbf{k})=\mathbf{s}(\mathbf{k}) \mathbf{e}^{\mathrm{G}|\mathbf{k}| / 2 \pi G} .
$$

After the Fourier transformation of $s_{D C}(k)$ we have removed the Lorentzian broadening of the Mössbauer lines and obtain the deconvoluted spectrum, $S_{D C}^{\prime}(v)$ as

$$
S_{D C}^{\prime}(v)=\frac{1}{2 \pi} \int s_{D C}(k) e^{-i k v} d k
$$

Using Eq. (5) and (6) we may write

$$
\begin{aligned}
S_{D C}^{\prime}(v)= & \frac{1}{2 \pi} \iint p(h, S)\left[\int \cos (k h) e^{-i k S_{e}-i k v} d k\right] d h d S= \\
& =\mathbf{S}_{\mathbf{D C}}^{\text {even }}(\mathbf{v})-\mathbf{S}_{\mathbf{D C}}^{\text {odd }}(\mathbf{v}) .
\end{aligned}
$$

After replacing the cosine and sine products with the proper cosine sums and using that $\frac{1}{2 \pi} \int \cos k x d k=\delta(x)$, the Dirac $\delta$-function, we obtain for the symmetric part of $S_{D C}(v)$ :

$$
\begin{aligned}
S_{D C}(v) & =S_{D C}^{\text {even }}(v)=\iint p(h, S) \frac{1}{4}[\delta(h+s+v)+\delta(h-s+v)+ \\
& +\delta(-h+S+v)+\delta(-h-s+v)] \text { dhdS }
\end{aligned}
$$

while the asymmetric part of the $S_{D C}(v)$ is given by

$$
\begin{aligned}
S_{D C}^{\text {odd }}(v) & =S_{D C}^{\text {odd }}(v)=-\iint p(h, S) \frac{1}{4}[\delta(h+s-v)-\delta(h-s-v)+ \\
& +\delta(h-S+v)-\delta(h+S+v)] \text { dhdS. }
\end{aligned}
$$

Eq. (9) and (10) are our basic equations which contain all information 
of our spectrum after the deconvolution of the Lorentzian broadening. It is clear that in principle the two-parameter distribution, $p(h, S)$ cannot be determined because only integrated $p(h, S)$ values at special parameter combinations are available. Only additional, artificial assumptions like limited range for the parameters used in Ref. 6 may allow the non-unique determination of $p(h, s)$.

\section{1. Special cases $(S<<h)$}

In most cases it can be assumed that one type of hyperfine interaction is dominant. In the case of ${ }^{57} \mathrm{Fe}$ these are the magnetic hyperfine interaction and quadrupole interaction for magnetic and paramagnetic spectra, respectively. In the following analysis the $s<h$ assumption will be used. The corresponding approximations of Eq. (9) and (10) are

$$
\begin{aligned}
s_{D C}(v) & =\int \frac{1}{2}[p(h=v, s)+p(h=-v, s)] d s= \\
& =\int p^{\text {even, } h}(h=v, s) d S
\end{aligned}
$$

and

$$
\begin{aligned}
\mathbf{S}_{\mathrm{DC}}^{\text {odd }}(\mathbf{v}) & =-\int \frac{1}{2}\left[\frac{\partial p}{\partial h}(\mathbf{h}=\mathbf{v}, \mathbf{S})-\frac{\partial p}{\partial h}(\mathbf{h}=-\mathbf{v}, \mathbf{S})\right] \mathbf{S d S} \\
& =-\int \frac{\partial \mathbf{p}}{\partial \mathbf{h}} \quad(\mathbf{h}=\mathbf{\text { odd } , \mathbf { h }}, \mathbf{S d S}
\end{aligned}
$$

\subsection{1. $h$ and $S$ are independent}

If there is no correlation between the hyperfine parameters, their distribution function can be factorized as

$$
\begin{aligned}
& p(h, S)=p_{h}(h) p_{S}(S), \text { where } \\
& \int p_{h}(h) d h=1 \text { and } \int p_{S}(S) d S=1 .
\end{aligned}
$$

In this case 


$$
\begin{aligned}
& s_{D C}(v)=p_{h}^{\text {even }}(h=v), \text { and } \\
& s_{D C}^{\text {odd }}(v)=-\bar{s} \frac{d p_{h}^{\text {odd }}}{d h}(h=v) \text {, where } \bar{s}=\int S p_{S}(S) d S .
\end{aligned}
$$

In all present applications $\overline{\mathrm{s}}=0$ will be assumed by the proper choice of the velocity - zero (which can be obtained without fitting via the weighted average of the spectrum). Thus the hyperfine parameters are correlated when $\mathrm{s}_{\mathrm{DC}}^{\text {odd }}(\mathrm{v}) \neq 0$.

\subsection{2. $h$ and $S$ are correlated}

In this case there is a functional connection between the two parameters of the distribution, i.e. $s=s(h)$. If the distribution of $h$ is given by $p(h)$, where $\int p(h) d h=1$ then the distribution of $s$ is given by

$$
p_{S}(S)=\frac{p\left(S^{-1}(S)\right)}{\frac{d S}{d h}\left(S^{-1}(S)\right)}
$$

where $h=S^{-1}(S)$ means the inverse function of $S$. The appropriate versions of Eq. (11) and (12) are the following:

$$
\begin{aligned}
s_{D C}(v) & =p^{\text {even }}(h=v) \text {, and } \\
S_{D C}^{\text {odd }}(v) & =-\left.\frac{d}{d h}\left(S(h) p^{\text {odd }}(h)\right)\right|_{h=v}= \\
& =-\left[\frac{d S}{d h}(h=v) p^{\text {odd }}(h=v)+S(h=v) \frac{d p}{d h}^{\text {odd }}(h=v)\right]
\end{aligned}
$$

If for $h>0$ the symmetric and asymmetric part of $p(h)$ are identical (i.e. $p(-|h|) \equiv 0$ ) and the correlation between $S$ and $h$ is linear, Eq. (18) offers an immediate direct determination of $\mathrm{dS} / \mathrm{dh}$ : it is related to the value of $s_{D C}^{\text {odd }}(v)$ at the $v_{m}$-value where $p(h)$ has its maximum, i.e.

$$
\frac{d S}{d h}=-s_{D C}^{\text {odd }}\left(v_{m}\right) / S_{D C}\left(v_{m}\right)
$$

\subsection{Illustration}

In the following simulation we will assume that $p(h, S)$ is a one-parameter distribution having Gaussian shape, i.e. 


$$
p(h, S)=p(h=H, S \equiv 0)=p(H)=e^{-\frac{1}{2}\left(\frac{H-H_{0}}{\sigma}\right)^{2}},
$$

where $\mathrm{H}_{0}=70, \sigma=10$. The half-linewidth of the Lorentzian components in Eq. (3) was chosen to be $G=4$. The Fourier transformed spectrum calculated on the base of Eq. (2) is given by

$$
\mathbf{s}(\mathbf{k}) \sim \mathrm{e}^{-\frac{1}{2} \mathbf{k}^{2} \sigma^{2}} \mathrm{e}^{-\mathrm{G}|\mathbf{k}|} \cos \mathbf{k H} \mathrm{H}_{0}
$$

If the linewidth used for the deconvolution of $s(k)$ is given by $\mathrm{G}_{\mathrm{DC}}$ ' where $\Delta G=G_{D C}-G>0$, the deconvoluted spectrum is given by

$$
\begin{gathered}
S_{D C}(v) \sim e^{\frac{1}{2}\left(\frac{\Delta G}{\sigma}\right)^{2}}\left[e^{-\frac{1}{2}\left(\frac{v-H_{0}}{\sigma}\right)^{2}} \cos \left(v-H_{0}\right) \frac{\Delta G}{\sigma^{2}}+\right. \\
\left.+e^{\frac{v+H_{0}}{\sigma}\left(\frac{H^{2}}{\sigma}\right)^{2}} \cos \left(v+H_{0}\right) \frac{\Delta G}{\sigma^{2}}\right]
\end{gathered}
$$

if $\Delta \mathbf{G} / \sigma<1$.

The successive steps of the evaluation are shown in Fig. 1. (Here and through the whole numerical work the integrals are replaced by the corresponding sums). The starting $p(H)$ is regained from the $S(v)$ spectrum of $F i g$. $1 b$ in Fig. Ie as a result of the above decomposition process $\left(G_{D C}=G\right.$, i.e. $\Delta \mathbf{G}=0$ was used).

\subsection{Limitations}

The fundamental step in deducing the basic equations (9) and (10) was that the $\int \cos (k x) d k$ type of integrals were replaced by the proper $\delta(x)$ delta-functions. This is valid if the boundaries are ${ }^{+\infty}$ or if $s_{D C}(k)$ is identically zero on limited boundaries. If we apply a finite cut-off at a $k_{\max }$ value, the above-mentioned integrals had to be replaced with $\sin \left(k_{m} x\right) / k_{m}$ of expressions. This finite cut-off will result in a cut-off oscillation in $S_{\mathrm{DC}}^{\prime}(v)$ the amplitude of which is determined by the value of $s_{\mathrm{DC}}\left(\mathrm{k}_{\mathrm{max}}\right)$ and decreasing like $1 / v$ for large $v$-values. The period of the oscillations is given by $2 \pi / k_{\max }$. Also the finite cut-off will result in a broadening of the distribution functions in $S_{D C}(v)$ if $s_{D C}(k)$ is not small enough above $k_{\max }$ because of the neglection of the high frequency components. 
In the given illustration of Fig. 1 the use of $k_{\max }=0.4 \mathrm{has} \mathrm{re-}$ sulted in this type of cut-off oscillation with an amplitude of $3.10^{-3}$ which cannot be observed on the figure and within this error the original $p(H)$ and the deconvoluted $S_{D C}(v)$ were identical.

The most serious limitation of this method originates from the statistical fluctuation of the spectra. The deconvolution process will result in a tremendous amplification of this noise because of the multiplication with $e^{G|k|}$. Thus the possible maximum cut-off value is determined alone by the noise-to-signal ratio, W of the spectra. This $k_{\max }$ value on the other hand will limit the minimum width of the distribution, $\sigma_{\text {min }}$ which can be evaluated without deforming the distribution. The condition of undistorted reproduction of the distribution is that 1 ts Fourier transformed function is small at the cut-off frequency, 1.e. assuming Gaussian shape for the distribution:

$$
e^{-\frac{1}{2} \mathbf{k}_{\max }^{2} \sigma_{\min }^{2}<w . ~}
$$

A natural choice of $k_{\max } i s e^{-G k_{\max }} \succsim w$, which gives the condition:

$$
\frac{\sigma_{\min }}{G}>\sqrt{\frac{-2}{\ln W}}
$$

Typical values of $\sigma_{\mathrm{min}} / \mathrm{G}$ from Eq. (24) are $0.82,0.66$ and 0.54 for $\mathrm{W}=$ $0.05,0.01$ and 0.001 , respectively. That is the practical 1 imit for the width of the narrowest distribution which can be evaluated with this method is about $\sigma_{\text {min }} \gtrsim G / 2$.

The before-discussed difficulties are illustrated with the case of crystalline $\mathrm{Zr}_{3} \mathrm{Fe}$ in Fig. 2. The Mössbauer spectrum consists of a we11resolved quadrupole doublet [9], that is the distribution of quadrupole splitting is a delta-function, its width is zero. According to this, the deconvoluted Fourier transformed spectrum, $s_{D C}(k)$ is a cosine-function without damping (Fig. 2c). If the cut-off takes place at too small $k_{\max }$ value strong cut-off oscillation with decreasing amplitude results (Fig. 2d). Also the distribution function is considerably broadened - in the example of Fig. 2d its width is larger than that of the spectrum. For increasing $k_{\max }$ values the evaluated width of the distribution is decreasing like $1 / k_{\max }$ and the effect of cut-off oscillations is suppressed 
by the amplified effect of the noise. In Fig. $2 f$ the width of the distribution $1 \mathrm{~s} 0.04 \mathrm{~mm} / \mathrm{s}(\sim \mathrm{G} / 4)$ but about half of the curve is noise.

It is worth to emphasize that there is an inner control possibi1ity in this Fourier deconvolution method: when it is incorrectly used for the evaluation of too narrow distribution (in the sense of the inequality (24)) the evaluated distribution (or a certain part of 1t) will change as a function of the chosen $k_{\max }$.

In the following point a natural selection of the best $k_{\max } v a l u e$ and typical applications will be presented.

\section{Applications}

This method can be applied for most amorphous and a large number of disordered crystalline systems containing iron. In the case of ${ }^{57} \mathrm{Fe}$ the dominant hyperfine interaction parameter is the hyperfine field or quadrupole splitting for magnetic or paramagnetic spectra, respective1y. The isomer shift is often only a minor perturbation.

The results of the present Fourier deconvolution method will be compared to those obtained by the binomial distribution method $|5|$. The BD method was chosen for this comparison because the correlation between the hyperfine parameters is easily included. The $p(h)$ distribution of the dominant hyperfine interaction $\mathrm{h}$ is approximated by a binomial distribution

$$
p(x, n)=\left(\begin{array}{l}
z \\
n
\end{array}\right) x^{n}(1-x)^{z-n}, n=0,1 \ldots z
$$

with

$$
h(n)=h_{0}+n \Delta h,
$$

and

$$
p(h(n))=p(x, n) / \Delta h .
$$

The parameter $\mathrm{z}$ is arbitrary (usually $\mathrm{z}=20$ was chosen). A least-square fitting procedure determines the value of the shape parameter $x$, the sampling interval $\Delta h$ and $h_{0}$. Linear correlation with the other parameter $s$ is included via the relation 


$$
\mathbf{s}(\mathrm{n})=\mathbf{s}_{0}+\mathbf{n} \Delta \mathbf{S}
$$

and the distribution of $S i s g i v e n$ by $p(S(n))=p(x ; n) / \Delta S$. The values of $S_{0}$ and $\Delta S$ are again determined by the least-square fitting procedure and $\frac{d S}{d h}$ is given by $\frac{\Delta S}{\Delta h}$. More complicated spectra can be described with the combination of more binomial distributions [5].

Typical Mössbauer spectra of ferromagnetic and paramagnetic amorphous alloys will be analysed in the following sections.

\subsection{Ferromagnetic cases}

The two investigated cases are characteristic of the "narrow" (Fe $68 \mathrm{Co}_{10} \mathrm{~B}_{12} \mathrm{Si}_{10}$ ) and "broad" ( $\mathrm{Fe}_{68} \mathrm{~V}_{10} \mathrm{~B}_{12} \mathrm{Si}_{10}$ ) type of hyperfine field distributions. These spectra are shown in Fig. 3 and some of the results of the BD analysis were published elsewhere [10]. The Fourier deconvolution will be performed on the 2 and 5 lines of these spectra which were obtained by using the spectrum substraction method [5]: a linear combination of two spectra with different relative intensities of the lines 2 and 5 was taken in such a way that the 1,6 and 3,4 lines were removed by adjusting the outer - free of overlap - part of the intensity of lines 1 and 6. The two spectra were recorded in the usual geometry, in a small external field $(\approx 200$ 0e) parallel to the ribbon plane and without external field in which case the stress between the amorphous ribbon and the adhesive tape turns most of the magnetic moments out of the ribbon plane [11] suppressing the intensities of the second and fifth lines. Using the $p(H)$ obtained from these separated 2 and 5 lines by the BD method and also by Window's method [1] the original spectra could be fitted with one free parameter: the (average) relative intensity of lines 2 and 5 , thus justifying the procedure. The advantage of this spectrum substraction method is that the systematical errors connected with the a priori unknown relative intensity of lines 2 and 5 are ruled out $[12,13]$ and significantly simplifies the interpretation of the results of the Fourier deconvolution. Also difficulties caused by the too small broadening of the lines 3 and 4 in the case of narrow $p(H)$ are avoided this way. (Because of the unfavorable g-factors the $\sigma$ width of $p(H)$ is scaled to 0.158 o for these lines).

For the second and fifth lines of the six-line pattern the line positions are given by Eq. (3) if 


$$
h=0.578 H \text { and } S=I S-\frac{1}{2} \Delta E_{Q}
$$

where the proper g-factor combination is used and it is assumed that $\Delta \mathbf{E}_{\mathbf{Q}} \ll \mathbf{H}$.

\subsubsection{Amorphous $\mathrm{Fe}_{68} \mathrm{Co}_{10} \mathrm{~B}_{12} \mathrm{Si}_{10}$}

Fig. 4 a shows the separated second and fifth lines of the spectrum of Fig. 3a. The deconvoluted Fourier transformed spectrum $s_{D C}(k)$ of Fig. 4c clearly shows that before the strong amplification of the noise there is an interval where $s_{\mathrm{DC}}(\mathrm{k}) \sim 0$. (For the deconvolution the linewidth of the Fe calibration ( $G=0.15 \mathrm{~mm} / \mathrm{s})$ was used). The back-transformations from this interval differ only in the amplitude and frequency of the oscillations determined by the $k_{\max }$ value, but the shape of the peak in $S_{D C}(v)$ is not influenced (Figs. 4d to $f$ ). The hyperfine field distribution $\mathrm{p}(\mathrm{H})$ is obtained from $\mathrm{S}_{\mathrm{DC}}(\mathrm{v})$ by rescaling and normalizing the curve. For the $k_{\max }$ values of Figs. $4 d$ to $f$ these $p(H)$ curves are shown in Fig. $5 a$ and they are identical apart from differences of the order of their noise. Also the comparison of the $p(H)$ evaluated by the Fourier deconvolution with that obtained from the fit to the spectrum by the BD method shows that they are identical within the error of the evaluations (Fig. 6a). This comparison convincingly proves the reliability of the parameterless Fourier deconvolution process.

There is a simple criterion for the selection of the optimum $\dot{k}_{\max }$ value in terms of the goodness parameter, $g$ which is defined as

$g=\left(\mathrm{A}^{+}-\mathrm{A}^{-}\right) /\left(\mathrm{A}^{+}+\mathrm{A}^{-}\right)$, where $\mathrm{A}^{+}$and $\mathrm{A}^{-}$are the areas with the

corresponding $\operatorname{sig} n$ under $S_{D C}(v)$. Since the distribution functions are positive definite by definition the deviation between $A$ and its absolute value is characteristic of the cut-off and noise oscillations. $g=0$ at $k_{\max }=0$ and $1 t$ would increase asymptotically to 1 if the noise would be absent. The amplification of noise at large $k_{\max }$ values on the other hand will result in $g=0$. Thus $g$ has a maximum as a function of $k_{\max }$ where is the optimum value of $k_{\max }$. Fig. 7 shows that in the present case there is a broad maximum in $g$ around $k_{\max }=9.42 \mathrm{~s} / \mathrm{mm}$ where the $\mathrm{g}-\mathrm{values}$ are above 0.9. This is a typical value for proper deconvolutions. On the 
other hand, in the former case of crystalline $\mathrm{Zr}_{3} \mathrm{Fe}$ the $\mathrm{g}$-values are around 0.5 - clearly indicating the improper quality of this deconvolution.

Fig. 5b shows the obtained $p(H)$ distributions when different $G_{D C}$ linewidths were used in the deconvolution. All curves were obtained with the same $k_{\max }=8.08 \mathrm{~s} / \mathrm{mm}$ to have the oscillations in identical positions. As it is expected on the base of Eq. (22) a definite narrowing of $\mathrm{p}(\mathrm{H})$ is observed for increasing $\mathrm{G}_{\mathrm{DC}}$. Also the amplitude of the noise has increased. However, even with two times larger $G_{D C}(0.30$ $\mathrm{mm} / \mathrm{s}$ ) than the linewidth of the calibration, no structure (new peaks) appears in $\mathrm{p}(\mathrm{H})$. This is contrary to the results obtained by the method of Window [1] where decomposition with large linewidths results in the appearance of new peaks in $\mathrm{p}(\mathrm{H})[3,4,14]$ which we had to attribute to the artifact of the least-square fitting procedure. Also Fig. 5b and Eq. (22) show that small deviation of $G_{D C}$ from $G$ results only in small distortion of the deconvoluted $\mathrm{p}(\mathrm{H})$.

\subsubsection{Amorphous $\mathrm{Fe}_{68} \mathrm{~V}_{10}-\mathrm{B}_{12} \frac{\mathrm{Si}}{10}$}

Fig. 8a shows the separated second and fifth lines of the spectrum of Fig. 3b. The hyperfine field distribution is more broad here than in the former case. According to this ${ }^{{ }_{D C}}(k)$ is nearing to zero more quickly (Fig. 8c). The $p(H)$ distributions calculated for different $k_{\max }$ values are again identical within their noise (Fig. 8f). The comparison with the p(H) obtained by the BD method shows that they are identical within the error of evaluation (Fig. 9a).

\subsection{Paramagnetic cases}

Two room temperature spectra of amorphous alloys will be investigated. It is typical for these cases that the isomer shift perturbation is much smaller than the quadrupole splitting, i.e.

$$
\mathrm{h}=\frac{\Delta \mathrm{E}_{\mathrm{Q}}}{2}=\mathrm{Q} \text { and } \mathrm{S}=\mathrm{IS} \text {. }
$$

The line positions are given by Eq. (3). 


\section{2.1. Amorphous $\mathrm{Zr}_{3} \mathrm{Fe}$}

F1g. 10 shows the room temperature Mössbauer spectrum of melt-quenched amorphous $\mathrm{Zr}_{3} \mathrm{Fe}$ together with the deconvolution process. The values of $g$ are shown in Fig. 7. again there is a $\mathrm{k}_{\max }$-interval where the $\mathrm{g}-$ values are above 0.9. The form of $\mathrm{S}_{\mathrm{DC}}(\mathrm{v})$ is identical for different $\mathrm{k}_{\max }$ values within the error of the determination (Fig. 10d and e). The quadrupole splitting distributions $p(Q)$ obtained after normalization are in general in good agreement with that obtained by the BD method from the fitting of the spectrum (Fig. 11).

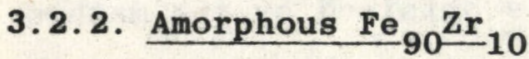

Fig. 12 shows the room temperature Mössbauer spectrum of melt-quenched amorphous $\mathrm{Fe}_{90} \mathrm{Zr}_{10}$ together with the deconvolution process. The $p(Q)$ obtained from $S_{D C}(v)$ after normalization is in general in good agreement with those obtained by the BD method from the fitting of the spectrum (Fig. 13).

\subsection{Correlation between the hyperfine parameters}

In the previous applications only the even part of the Fourier transformed spectra was taken into account. Since the velocity-zero was chosen in such a way that $\overline{\mathrm{s}}=0$, the odd part of the Fourier transformed spectra should be identically zero if the hyperfine parameters are uncorrelated. However the parameters are correlated as it is obvious from the asymmetric shape of the spectra. According to Eq. (18) the odd part of the deconvoluted spectrum $s_{D C}^{\text {odd }}(v)$ gives limited information on this correlation and on the asymmetric part of the dominant distribution. In the following this information will be explored for the investigated cases.

\subsubsection{Amorphous $\mathrm{Fe}_{68} \mathrm{Co}_{10}-_{12}{ }_{10}{ }_{10}$ and $\mathrm{Fe}_{68} \mathrm{~V}_{10}-_{12} \frac{\mathrm{Si}}{10}$}

The odd part of the Fourier deconvoluted second and fifth lines of the Mössbauer spectrum of amorphous $\mathrm{Fe}_{68} \mathrm{Co}_{10} \mathrm{~B}_{12} \mathrm{Si}_{10}$ is shown in Fig. $14 \mathrm{c}$. Similar result was obtained in the case of amorphous $\mathrm{Fe}_{68} \mathrm{~V}_{10}{ }^{\mathrm{B}}{ }_{12} \mathrm{Si}{ }_{10}$. It is clear from Fig. 14c that the correlation between the hyperfine field and the $S=I S-\frac{1}{2} \Delta E_{Q}$ combination of isomer shift and quadrupole splitting is rather weak. Since in both cases the hyperfine field distribution 
does not extend to $H=0$ values, it is probably a good approximation to assume that $p^{\text {even }}(H) \equiv p^{\text {odd }}(H)$. Then, if the correlation is linear between $S$ and $H, d S / d H$ can be obtained directly from the deconvoluted spectrum. According to Eq. (19) and Eq. (29):

$$
\frac{d S}{d H}=-0.578 s_{D C}^{\text {odd }}\left(v_{m}\right) / S_{D C}\left(v_{m}\right)
$$

at the $v_{m}$ value where $S_{D C}(v)$ (1.e. $p(h)$ ) has its maximum. $d S / d H=0.031$ and 0.042 was obtained for amorphous $\mathrm{Fe}_{68} \mathrm{Co}_{10} \mathrm{~B}_{12} \mathrm{Si}_{10}$ and $\mathrm{Fe}_{68} \mathrm{~V}_{10} \mathrm{~B}_{12} \mathrm{Si}_{10}$, respectively.

These values agree well with those deduced from the fits of the spectra with the $B D$ method, which are dS/dH $=\Delta S / \Delta H=0.023(7)$ and $0.027(6)$, respectively. It is worth to emphasize that these values differ both in magnitude and sign from the $d(I S) / d H-v a l u e s$ obtained in similar crystalline intermetallic compounds [15]. In those systems (1ike $\mathrm{Fe}_{3} \mathrm{~B} \mathrm{Fe}_{2} \mathrm{~B}$, FeB) it has been found that the absolute value of the hyperfine field has decreased with increasing isomer shift with a value of d(IS)/dH $=-0.038$. Since there is no evidence which would suggest that isomer shift and hyperfine field would be correlated differently in amorphous than in similar crystalline systems we had to conclude that the quadrupole splitting is also correlated with the hyperfine field. This conclusion is supported by the shape of the lines in the Mössbauer spectrum of amorphous $\mathrm{Fe}_{68} \mathrm{Co}_{10} \mathrm{~B}_{12} \mathrm{Si}_{10}$ in Fig. 3a: the width of lines 1 and 6 is about the same while the lines 2 and 5 are quite asymmetric. (For the lines 1 and $6 S=I S+\frac{1}{2} \Delta E$ ). $S i-$ milar result was obtained in amorphous $\mathrm{Fe}_{80} \mathrm{~B}_{20}[5]$.

The combination of the value of $d S / d H=d\left(I S-\frac{1}{2} \Delta E_{Q}\right) / d H=0.031$ with the crystalline $d(I S) / d H=-0.038$ results in $d\left(\frac{1}{2} \Delta E_{Q}\right) / d H \approx-0.07$ for this correlation. In crystalline orthorhombic $(\mathrm{Fe}, \mathrm{Ni})_{3}{ }^{\mathrm{B}}$ compounds a value of $\mathrm{d}\left(\frac{1}{2} \Delta \mathrm{E}_{\mathrm{Q}}\right) / \mathrm{dH}=-0.08(1)$ can be deduced $[16]$. The good agreement should be considered fortuitous because these values are quite sensitive for the actual topological arrangement of the atoms. The origin of the correlation between the hyperfine field and quadrupole splitting is the dipole contribution of the hyperfine field [17].

This result is quite contrary to the common view that in metallic glasses the quadrupole interaction is averaged out due to the randomness of the magnetization directions with respect to the electric field gradients. 


\subsubsection{Amorphous $\mathrm{Zr}_{3} \mathrm{Fe}$ and $\mathrm{Fe}_{90} \mathrm{Zr}_{10}$}

The odd parts of the Fourfer deconvoluted Mössbauer spectra of amorphous $\mathrm{Zr}_{3} \mathrm{Fe}$ and $\mathrm{Fe}_{90} \mathrm{Zr}_{10}$ are shown in $\mathrm{Figs.} 15 \mathrm{c}$ and $16 \mathrm{c}$, respectively. The correlation between isomer shift and quadrupole splitting is quite strong in both cases. Assuming linear correlation we can determine $d(I S) / d Q$ by using Eq. (19), if $p^{\text {even }}(Q) \equiv p^{\text {odd }}(Q)$. The values are -0.211 and +0.142 for amorphous $\mathrm{Zr}_{3} \mathrm{Fe}$ and $\mathrm{Fe}_{90} \mathrm{Zr}_{10}$, respectively. The fits of the spectra with the BD method has provided -0.213(12) and $+0.137(8)$, respectively. Again the agreement between the two independent determinations is quite good. The different sign and magnitude of $d(I S) / d Q$ in these systems suggest different electrostructure and possibly different atomic structure.

$\mathrm{s}_{\mathrm{DC}}^{\text {odd }}(\mathrm{v})$ was calculated within the present approximation by using the deduced values of $d S / d Q$ and $S_{D C}(v)$ with Eq. (18). The results are the dotted curves in the inserts of Figs. 11a and 13a. The overall agreement with the result of the Fourier deconvolution is satisfactory, however, the calculated curves are not asymmetric. The deviation is larger for $\mathrm{Fe}_{90} \mathrm{Zr}_{10}$ than for $\mathrm{Zr}_{3} \mathrm{Fe}$. This difference may be caused by the roughness of the linear correlation approximation at small $Q$ values. However, it is more probably that the dominant reason is that $p^{\text {even }}(Q) \neq p^{\text {odd }}(Q)$, i.e. the quadrupole distribution extends for negative values. The larger deviation for $\mathrm{Fe}_{90} \mathrm{Zr}_{10}$ can be correlated then with the larger $p(Q=0)$ value which indicates more contribution in. the negative $Q$-range. In this case the full $p(Q)$ distribution (for positive and negative $Q$-values) can be determined independently by using large external magnetic fields. However, the full $p(Q)$ can be determined also from the Fourier deconvolution if the form of the $S(Q)$ correlation is known. The information about $\frac{d}{d Q}\left[S(Q) p^{\text {odd }}(Q)\right]$ in $S_{D C}^{\text {odd }}(v)$ can be amplified at the expense of the information in $S_{D C}(v)$ by $\bar{s} \neq 0$ choice of the velocity-zero. For lack of direct experimental determination of $\mathrm{p}^{\text {odd }}(\mathrm{Q})$ (in external magnetic fields) no such analysis was here performed).

\section{Summary}

It has been shown that the Fourier deconvolution method gives more 
information about broad distributions without adjustable parameters than the least-square fitting procedures. If a dominant hyperfine interaction parameter can be selected the even part of the Fourier deconvoluted spectrum provides the even part of the distribution of this parameter. The odd part of the Fourier deconvoluted spectrum gives the derivative of the product of the odd part of this distribution with its correlation with other hyperfine parameters.

It is worth to emphasize that differences in the symmetric and antisymmetric part of the dominant distribution may be important when the parameter has both positive and negative values. This possibility is generally overlooked in fitting of very broad hyperfine field distributions (extending to zero fields) with Window's [1] method. The Fourier deconvolution method can provide both even and odd parts of the dominant distribution when the correlation with other parameters is known.

\section{Acknowledgement}

I am very grateful to $\mathrm{C}$. Bos for the computing work and useful suggestions. Enlightening discussions with H.J.F. Jansen, W. Hoving and F. van der Woude are acknowledged. I am indebted to K.H.J. Buschow, A.H. Davies and M.G. Scott for the samples which Mössbauer spectra were used for fllustration in this paper.

This work forms part of the research program of the Foundation for Fundamental Research on Matter (FOM), with financial support from the Netherlands Organization for the Advancement of Pure Research (ZWO). 


\section{References}

[1] B. Window, J. Phys. E: Sc1. Instrum. $\underline{4}$ (1971) 401.

[2] J. Hesse and A. Rubartsch, J. Phys. E: Sci. Instrum. $\underline{7}$ (1974) 526.

[3] G. Le Caër and J.M. Dubo1s, J. Phys. E: Sc1. Instrum. 12 (1979), 1081.

[4] H. Keller, J. Appl. Phys., to be published.

[5] I. Vincze, Solid State Commun. 25 (1978) 689.

[6] M.C.D. Ure and P.A. Flinn, Mössbauer Methodology, $\underline{7}$ (Plenum Press, New York, 1971) p. 245.

[7] D.L. Nagy and K. Kulcsàr, Proc. on Mössbauer Spectroscopy, Dresden, 1971, Vol. 2, p. 618.

[8] P. Levitz, D. Bonnin, G. Calas and A.P. Legrand, J. Phys. B: Sci. Instrum. 13 (1980) 427.

[9] I. Vincze, F. van der Woude and M.G. Scott, Solid St. Sommun. 37 (1981) 567.

[10] T. Kemèny, B. Fogarassy, I. Vincze, I.W. Donald, M.J. Besnus and H.A. Davies, Rapidly Quenched Metals IV, Sendai, 1981, to be published.

[11] A.M. van Diepen and F.J.A. den Broeder, J. Appl. Phys. 48 (1977) 3165.

[12] A.s. Scharama, Phys. Rev. B 23 (1980) 4784.

[13] I. Vincze, submitted to Phys. Rev. B.

[14] J.M. Dubois, G. Le Caër, A. Amamou and U. Herold, J. de Physique $\underline{41}$ (1980) C1-247.

[15] I. Vincze, M.C. Cadeville, R. Jesser and L. Takàcs, J. de Physique 35 (1974) C6-1676.

[16] T. Kemèny, I. Vincze, J. Balogh, L. Grànàssy, B. Fogarassy, F. Hajdu and E. Svàb, Proc. Conf. on Metallic Glasses: Science and Technology, Budapest, 1980, p. 231.

[17] G. Le Caër and J.M. Dubots, Phys. Stat. Sol. (a) 64 (1981) 275. 


\section{FIGURE CAPTIONS}

Fig. 1. Illustration of the Fourier deconvolution procedure. The theoretical p(H) (a) was used for the calculation of $S(v)$ (b). s(k) is the Fourier transformed spectrum (c). The deconvoluted Fourier transformed spectrum is $s_{D C}(k)$ (d) and after back-transformation the Lorentzian broadening was removed in $S_{D C}(v)$ (e). The maximum value of the curves was chosen to be 1 .

Fig. 2. Fourier deconvolution of the Mössbauer spectrum of crystalline $\mathrm{Zr}_{3} \mathrm{Fe}$. Notation as before. For the deconvolution the linewidth of the Fe calibration was used. Back-transformation is shown for different $k_{\max }$ values: $10.68 \mathrm{~s} / \mathrm{mm}$ (d), $26.71 \mathrm{~s} / \mathrm{mm}$ (e) and $42.74 \mathrm{~s} / \mathrm{mm}$ (f).

Fig. 3. Mössbauer spectra of amorphous $\mathrm{Fe}_{68} \mathrm{Co}_{10}^{\mathrm{B}} 12^{\mathrm{Si}} 10$ measured at $77 \mathrm{~K}$ (a) and amorphous $\mathrm{Fe}_{68} \mathrm{~V}_{10} \mathrm{~B}_{12} \mathrm{Si}_{10}$ measured at $5 \mathrm{~K}$ (b).

Fig. 4. Fourier deconvolution of the second and fifth lines of the Mössbauer spectrum of amorphous $\mathrm{Fe}_{68} \mathrm{Co}_{10} \mathrm{~B}_{12} \mathrm{Si}_{10}$ shown in Fig. 3a. Notation as before. Back-transformation is shown for different $k_{\max } v a l u e s: 8.08 \mathrm{~s} / \mathrm{mm}$ (d), $10.77 \mathrm{~s} / \mathrm{mm}$ (e) and $13.46 \mathrm{~s} / \mathrm{mm}$ (f).

Fig. 5. a, Hyperfine field distribution of $\mathrm{Fe}_{68} \mathrm{Co}_{10} \mathrm{~B}_{12} \mathrm{Si}_{10}$ calculated from the deconvoluted spectra $S_{D C}(v)$ of Figs. $4 d$ to $f$, for different $k_{\max }$ values: $8.08 \mathrm{~s} / \mathrm{mm}$ (dashed line), $10.77 \mathrm{~s} / \mathrm{mm}$ (continuous line) and $13.46 \mathrm{~s} / \mathrm{mm}$ (dots), respectively.

b, Hyperfine field distributions of $\mathrm{Fe}_{68} \mathrm{Co}_{10} \mathrm{~B}_{12} \mathrm{Si}_{10} \mathrm{calcu}-$ lated from the deconvoluted spectra $S_{D C}(v)$ where different linewidths were used in the deconvolution: $G_{D C}=$ $0.15 \mathrm{~mm} / \mathrm{s}$ (dashed line), $G_{D C}=0.225 \mathrm{~mm} / \mathrm{s}$ (dots) and $\mathrm{G}_{\mathrm{DC}}=0.30 \mathrm{~mm} / \mathrm{s}$ (continuous line), respectively, The value of $k_{\max }$ was the same $(8.08 \mathrm{~s} / \mathrm{mm})$ in these cases. 
F1g. 6. Hyperfine field distribution of $\mathrm{Fe}_{68} \mathrm{Co}_{10}{ }_{12} \mathrm{Si}_{10}$ obtained by the binomial distribution method (histogram) compared to that obtained by Fourier deconvolution with $k_{\max }=$ $9.42 \mathrm{~s} / \mathrm{mm}$ (dashed line) (a). The fit of the spectrum obtained by the BD method is also shown (b).

F1g. 7. Goodness parameter as a function of $\mathrm{k}_{\max }$ : amorphous $\mathrm{Fe}_{68} \mathrm{Co}_{10} \mathrm{~B}_{12} \mathrm{SI}_{10}(\bullet)$, the same in the case $\mathrm{G}_{\mathrm{DC}}=0.30 \mathrm{~mm} / \mathrm{s}$ (A), amorphous $\mathrm{Zr}_{3} \mathrm{Fe}(0)$ and crystalline $\mathrm{Zr}_{3} \mathrm{Fe}(+)$.

F1g. 8. Fourier deconvolution of the second and fifth lines of the Mobssbauer spectrum of amorphous $\mathrm{Fe}_{68} \mathrm{~V}_{10} \mathrm{~B}_{12} \mathrm{Si}_{10}$ shown in Fig. 3b. Notation as before, $S_{D C}(v)$ is shown for different $k_{\max }$ values: $5.36 \mathrm{~s} / \mathrm{mm}(d)$ and $10.73 \mathrm{~s} / \mathrm{mm}(e)$. The hyperfine fleld distribution calculated from the deconvoluted spectra is also shown for the different $k_{\max }$ values: $5.36 \mathrm{~s} / \mathrm{mm}$ (continuous line) and $10.73 \mathrm{~s} / \mathrm{mm}$ (dashed line) (f), respective$1 y$.

Fig. 9. Hyperfine field distribution of $\mathrm{Fe}_{68} \mathrm{~V}_{10}{ }^{\mathrm{B}} 12^{\mathrm{Si}} 10$ obtained by the binomial distribution method (histogram) compared to that obtained by Fourier deconvolution with $\mathrm{k}_{\max }=5.36 \mathrm{~s} / \mathrm{mm}$ (dashed line) (a). The fit of the spectrum obtained by the BD method is also shown (b).

Fig. 10. Fourier deconvolution of the room temperature Mössbauer spectrum of amorphous $\mathrm{Zr}_{3} \mathrm{Fe}$. Notation as before. $\mathrm{S}_{\mathrm{DC}}(\mathrm{v})$ is shown for different $k_{\max }$ values: $16.03 \mathrm{~s} / \mathrm{mm}$ (d) and $21.37 \mathrm{~s} / \mathrm{mm}$ (e).

Fig. 11. Quadrupole splitting distribution of amorphous $\mathrm{Zr}_{3} \mathrm{Fe}$ obtained by the $\mathrm{BD}$ method (histogram) compared to those obtained by Fourier deconvolution with $k_{\max }=16.03 \mathrm{~s} / \mathrm{mm}$ (dots) and with $k_{\max }=21.37 \mathrm{~s} / \mathrm{mm}$ (continuous line) (a). The fit of the spectrum obtained by the BD method is also shown (b). The insert shows $s_{D C}^{\text {odd }}(v)$ as obtained from the Fourier transformation (continuous line) and calculated by assuming linear correla- 
tion between $Q$ and IS as explained in the text (dots).

F1g. 12. Fourier deconvolution of the room temperature Mössbauer spectrum of amorphous $\mathrm{Fe}_{90} \mathrm{Zr}_{10}$. Notation as before. $\mathrm{S}_{\mathrm{DC}}(\mathrm{v})$ is shown for $k_{\max }=18.70 \mathrm{~s} / \mathrm{mm}$ (d).

F1g. 13. Quadrupole splitting distribution of amorphous $\mathrm{Fe}_{90} \mathrm{Zr}_{10}$ obtained by the BD method (the two histograms illustrate different samplings) compared to that obtained by Fourier deconvolution with $k_{\max }=18.70 \mathrm{~s} / \mathrm{mm}$ (continuous line) (a). The fit of the spectrum obtained by the $\mathrm{BD}$ method is also shown (b). The insert shows $s_{D C}^{\text {odd }}(v)$ as obtained from the Fourier transformation (continuous line) and calculated by assuming linear correlation between $Q$ and IS as explained in the text (dots).

Fig. 14. $\mathrm{s}^{\text {odd }}(\mathrm{k})$ is the odd part of the Fourier transformed second and fifth lines of the spectrum of amorphous $\mathrm{Fe}_{68} \mathrm{Co}_{10}{ }_{12} \mathrm{Si}_{10}$ (a). The odd part of the deconvoluted Fourier transformed spectrum is $s_{D C}^{\text {odd }}(k)$ (b) and after the back-transformation of $s_{\mathrm{DC}}^{\text {odd }}(\mathrm{k})$ the odd part of the deconvoluted spectrum is $\mathrm{s}_{\mathrm{DC}}^{\text {odd }}(\mathrm{v})(\mathrm{c})$. Here $\mathrm{k}_{\max }=9.42 \mathrm{~s} / \mathrm{mm}$ was used.

Fig. 15. Odd part of the Fourier deconvolution of the Mössbauer spectrum of amorphous $\mathrm{Zr}_{3} \mathrm{Fe}$. Notation as on Fig. 14. $\mathrm{k}_{\max }=$ $21.37 \mathrm{~s} / \mathrm{mm}$ was used.

Fig. 16. Odd part of the Fourier deconvolution of the Mössbauer spectrum of amorphous $\mathrm{Fe}_{90} \mathrm{Zr}_{10}$. Notation as on Fig. 14. $\mathrm{k}_{\max }=$ $18.70 \mathrm{~s} / \mathrm{mm}$ was used. 

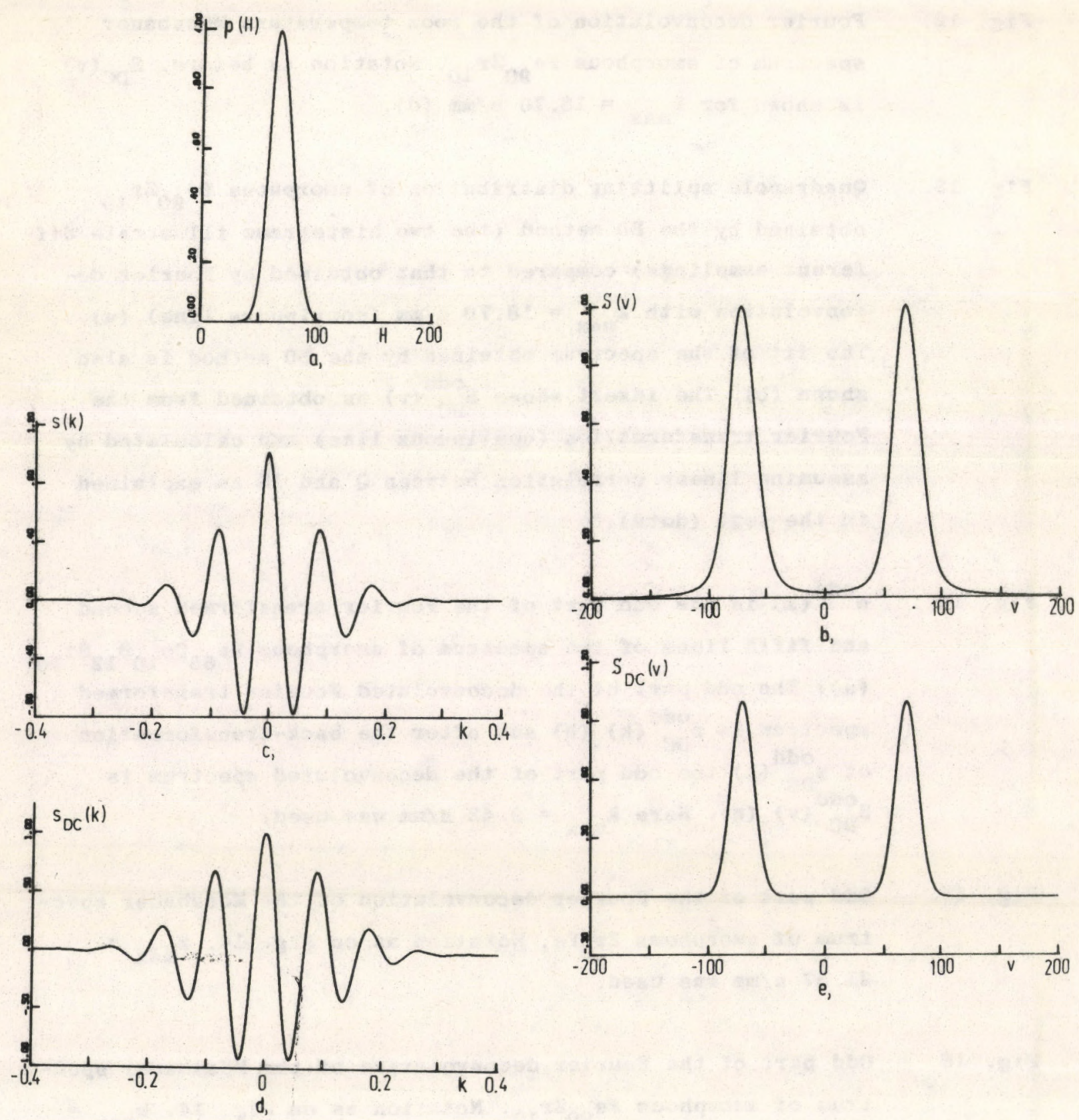

Fig. 1 

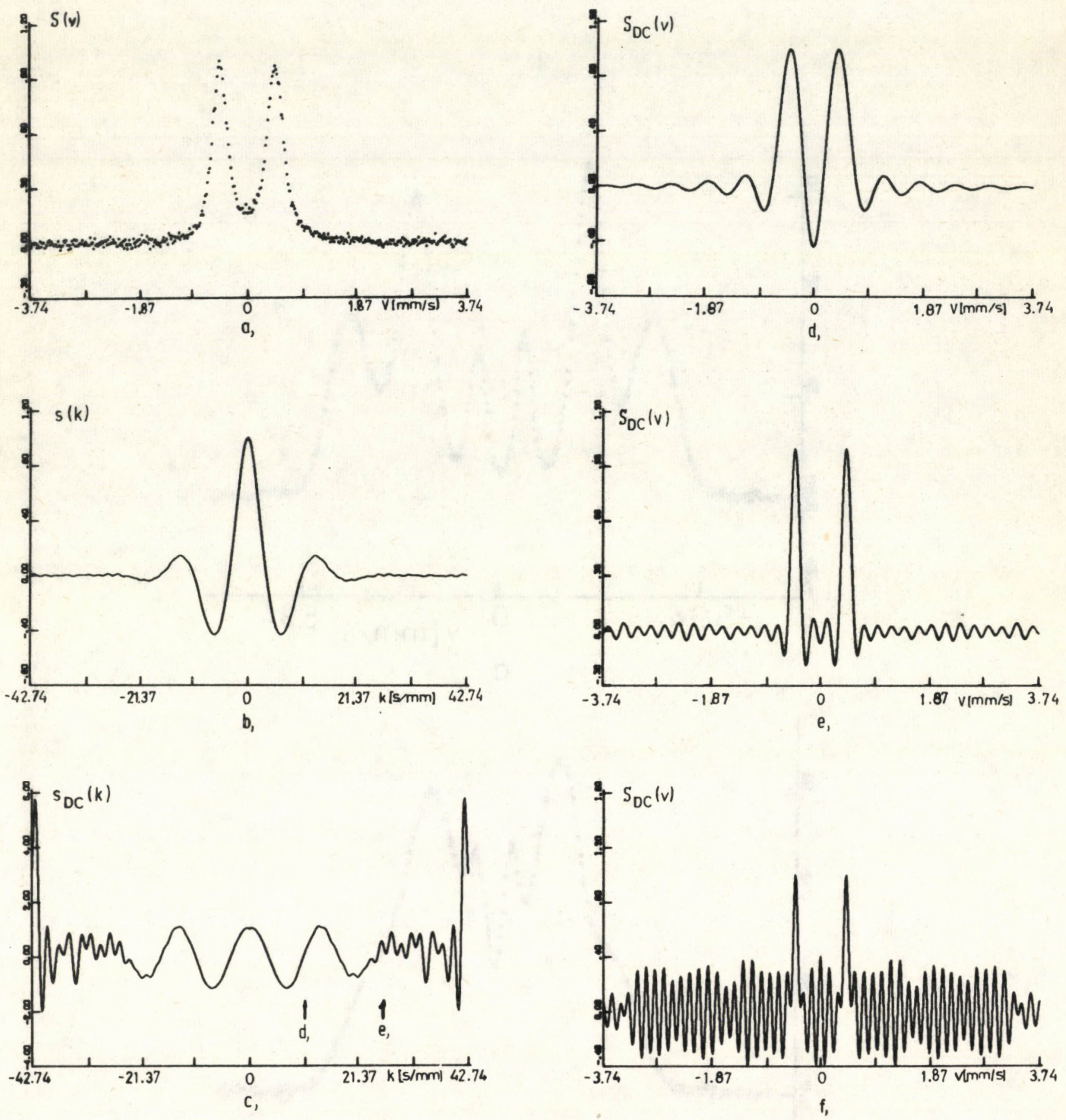

Fig. 2 
$-24-$
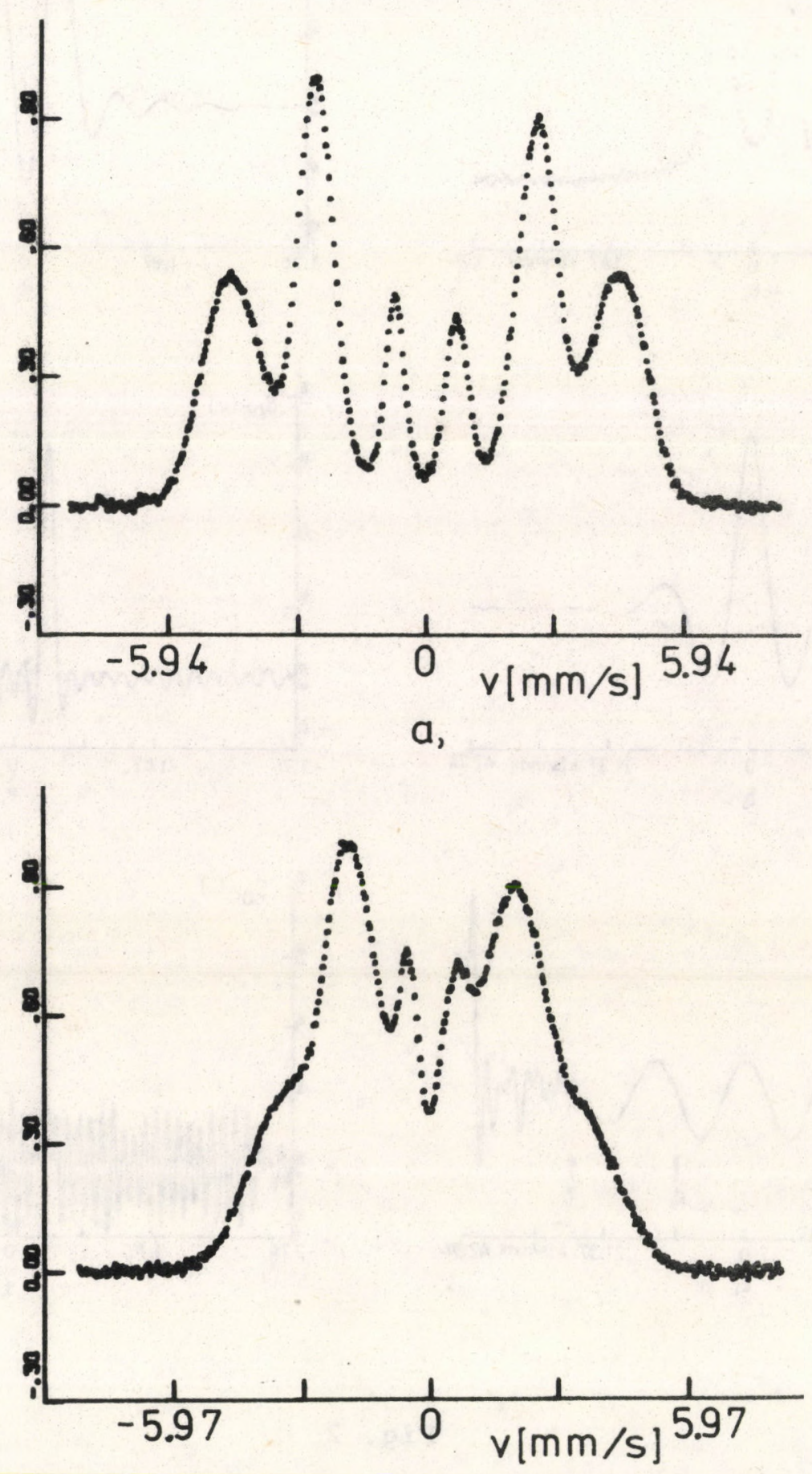

b,

Fig. 3 

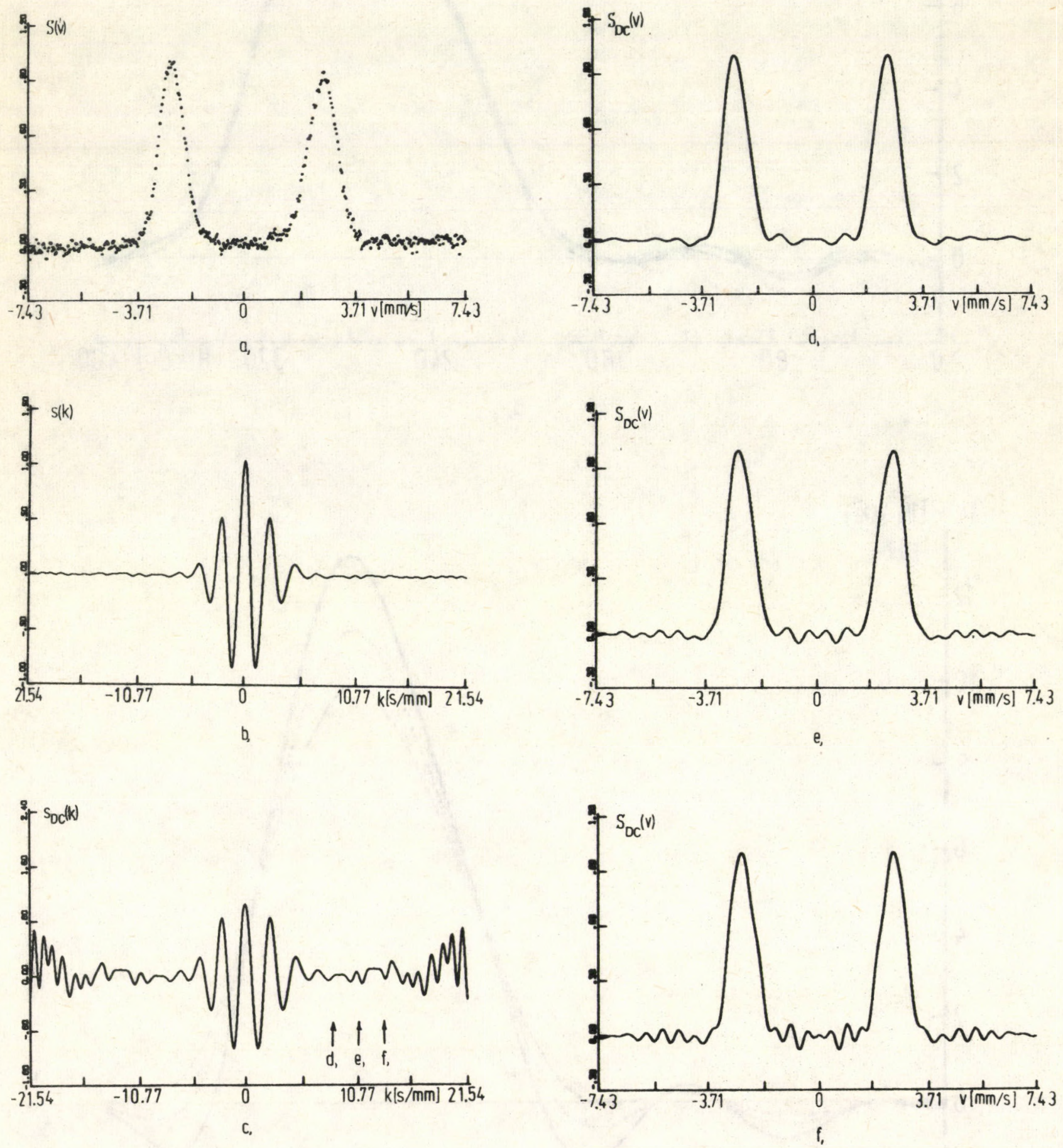

Fig. 4 

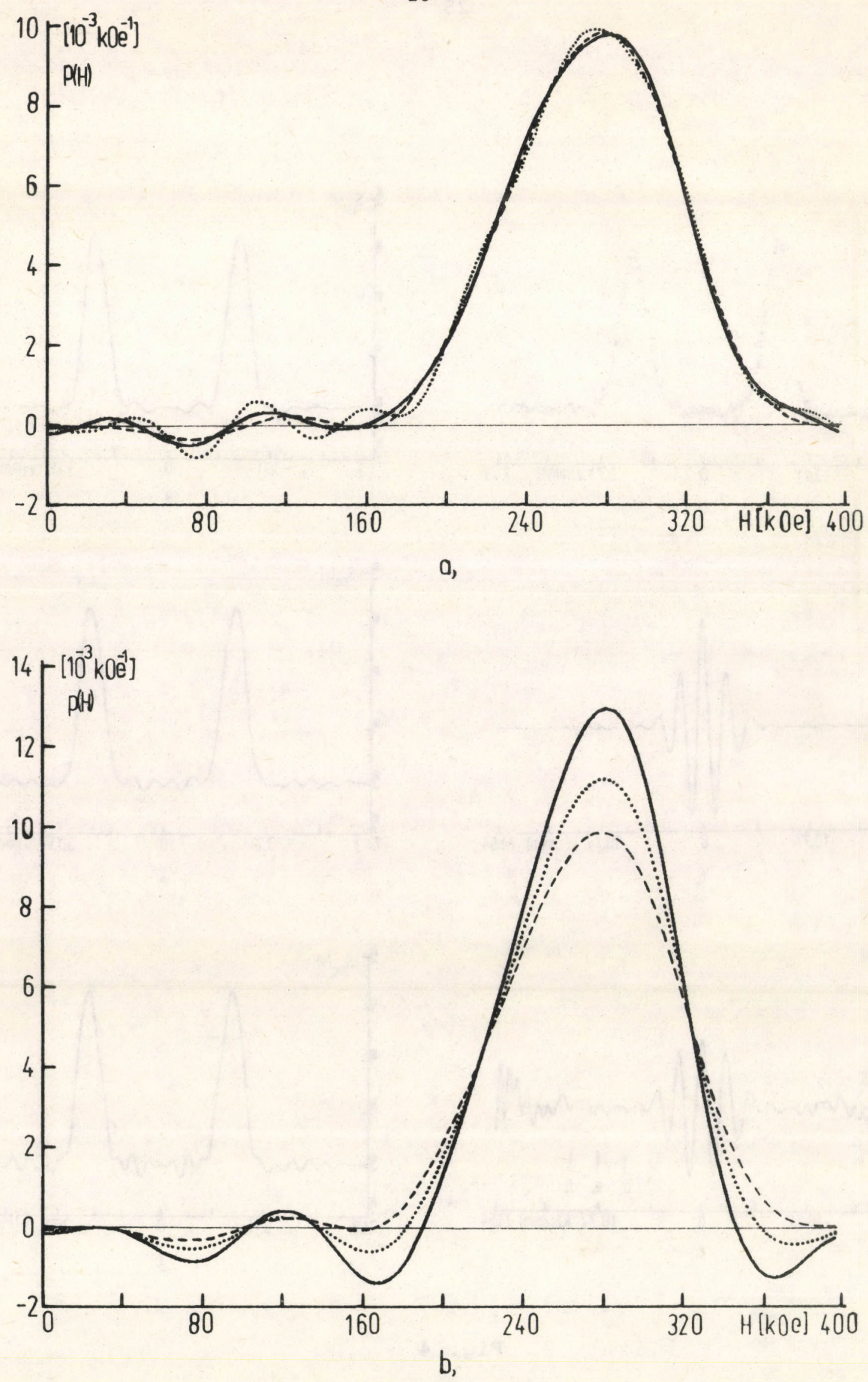

Fig. 5 

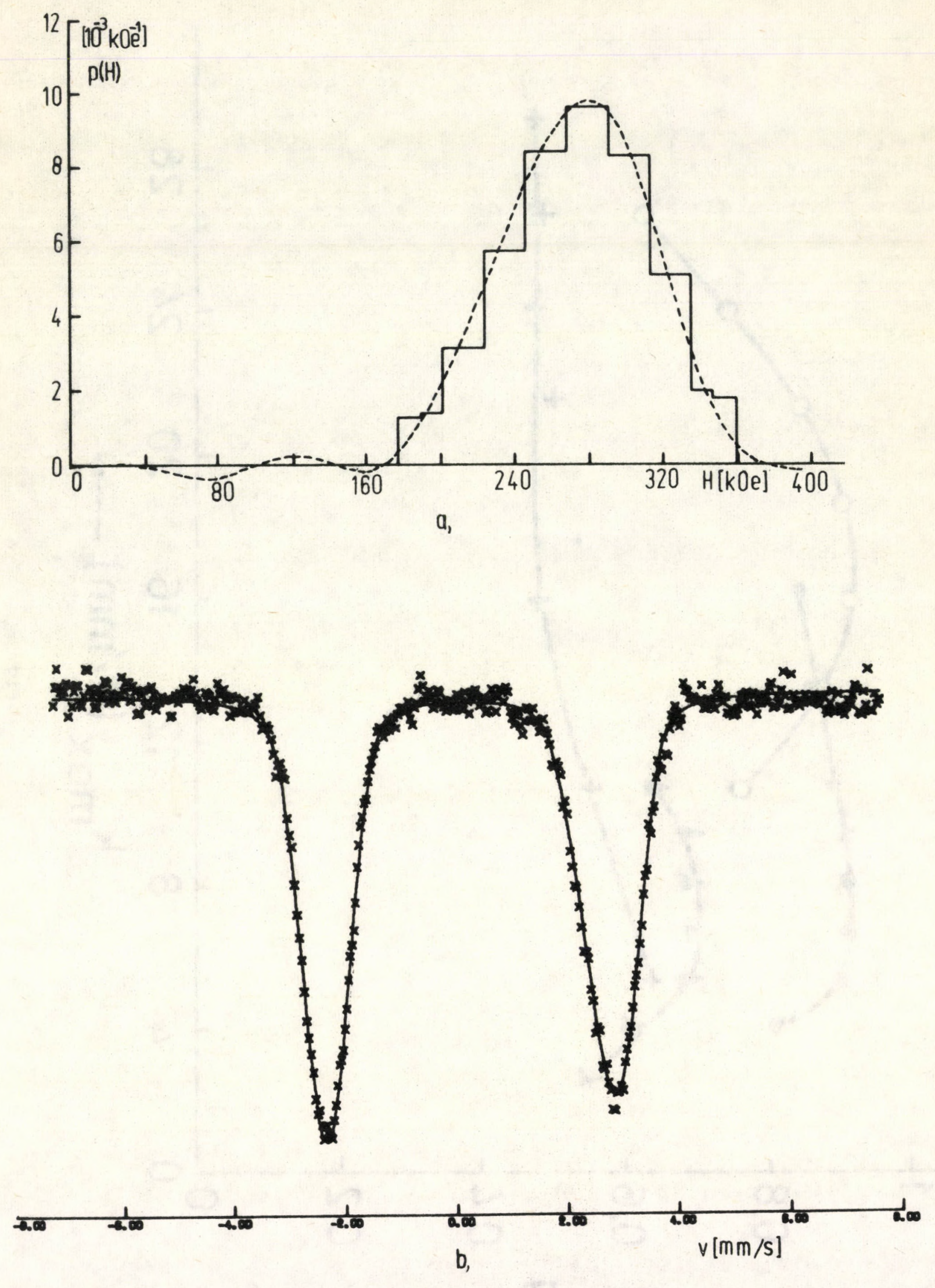

Fig. 6 


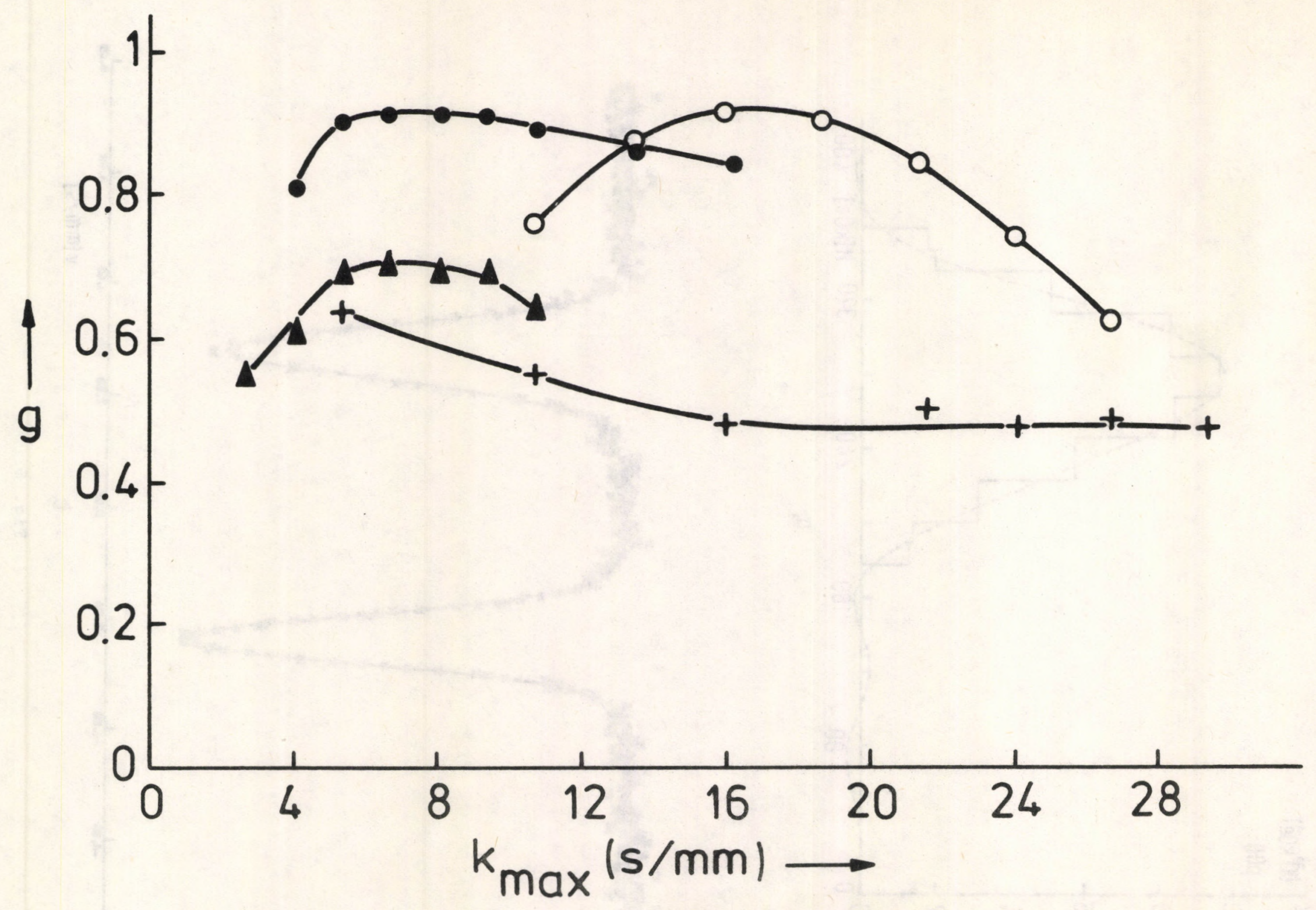



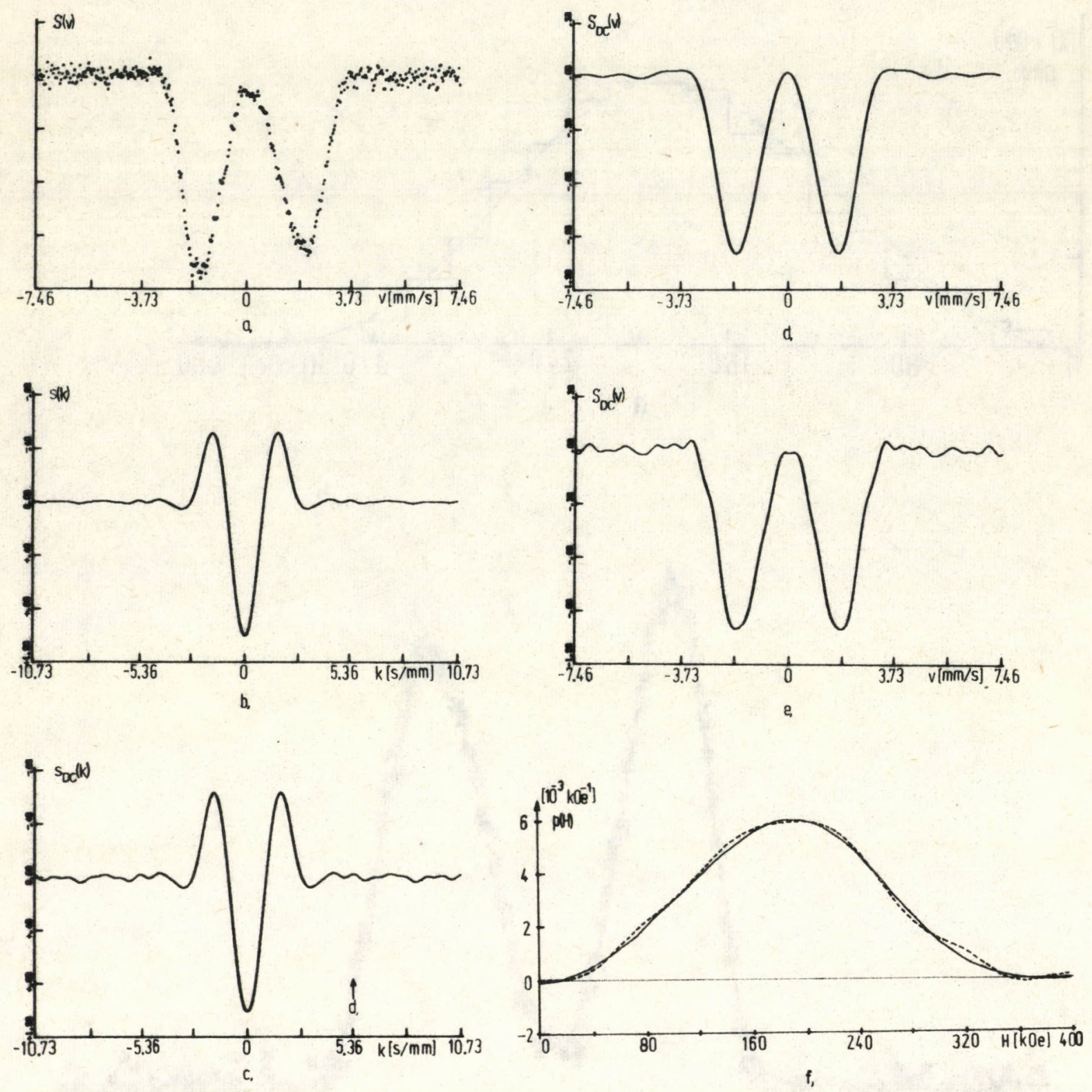

Fig. 8 

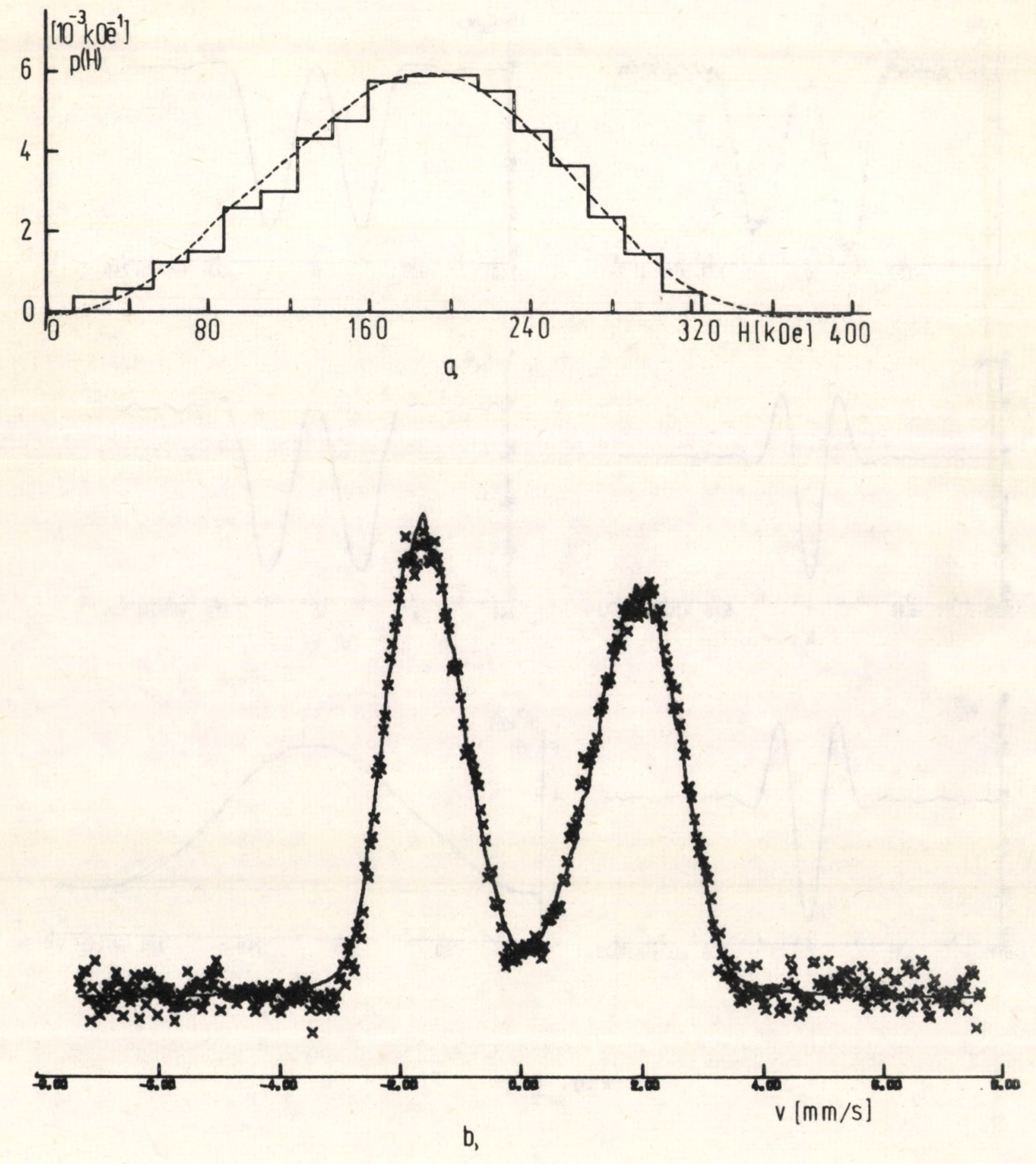

Fig. 9 

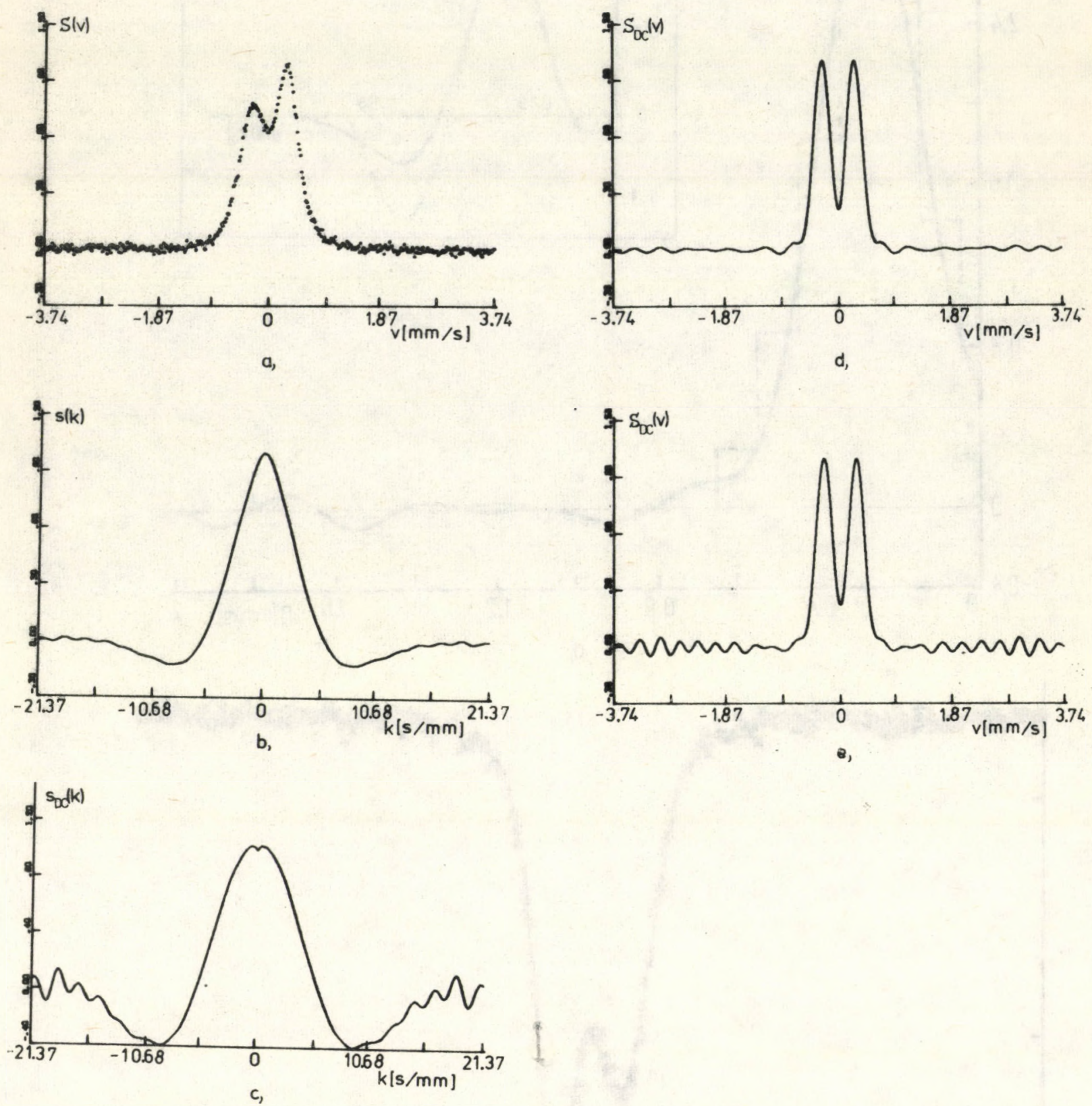

Fig. 10 

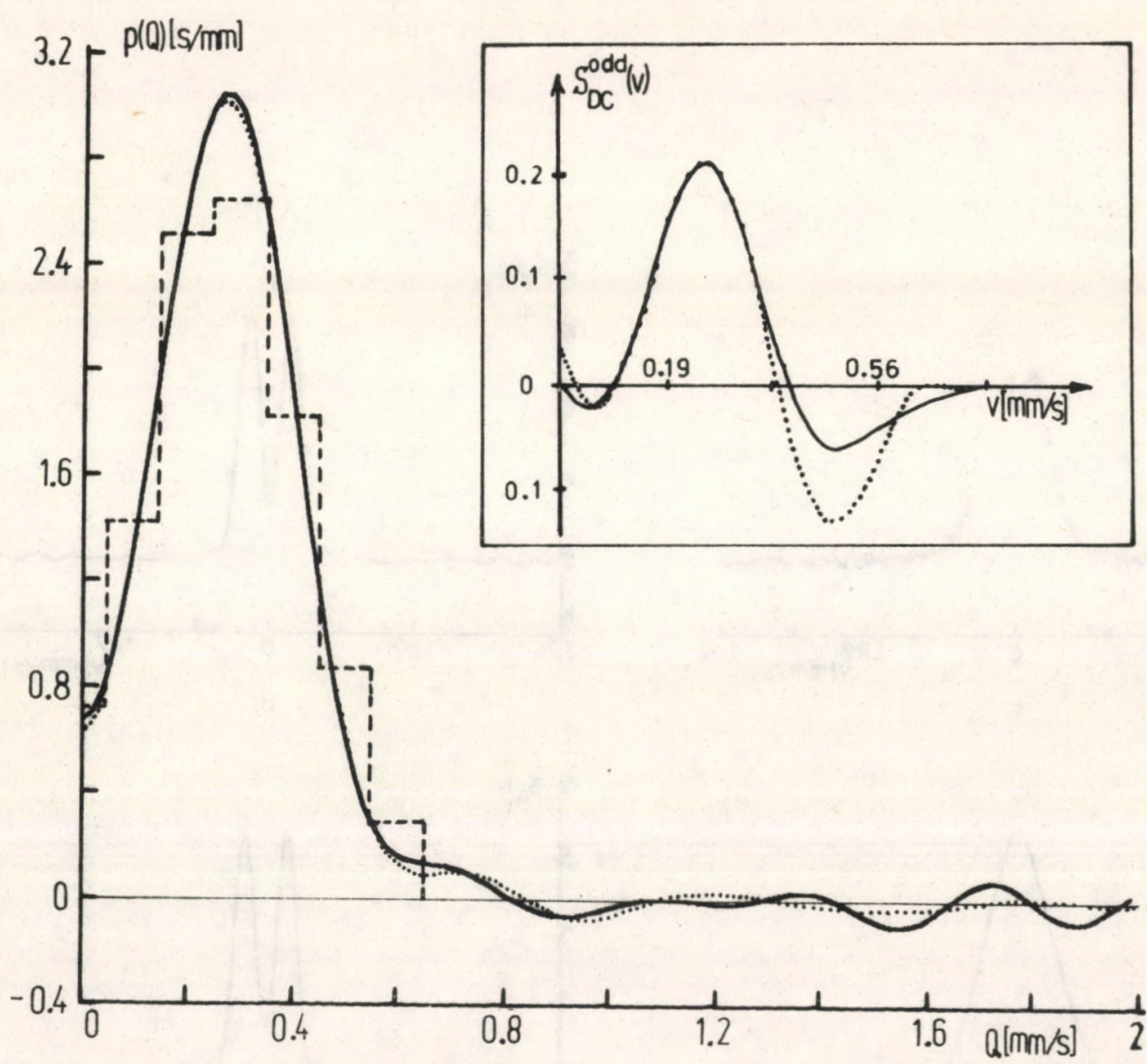

a,

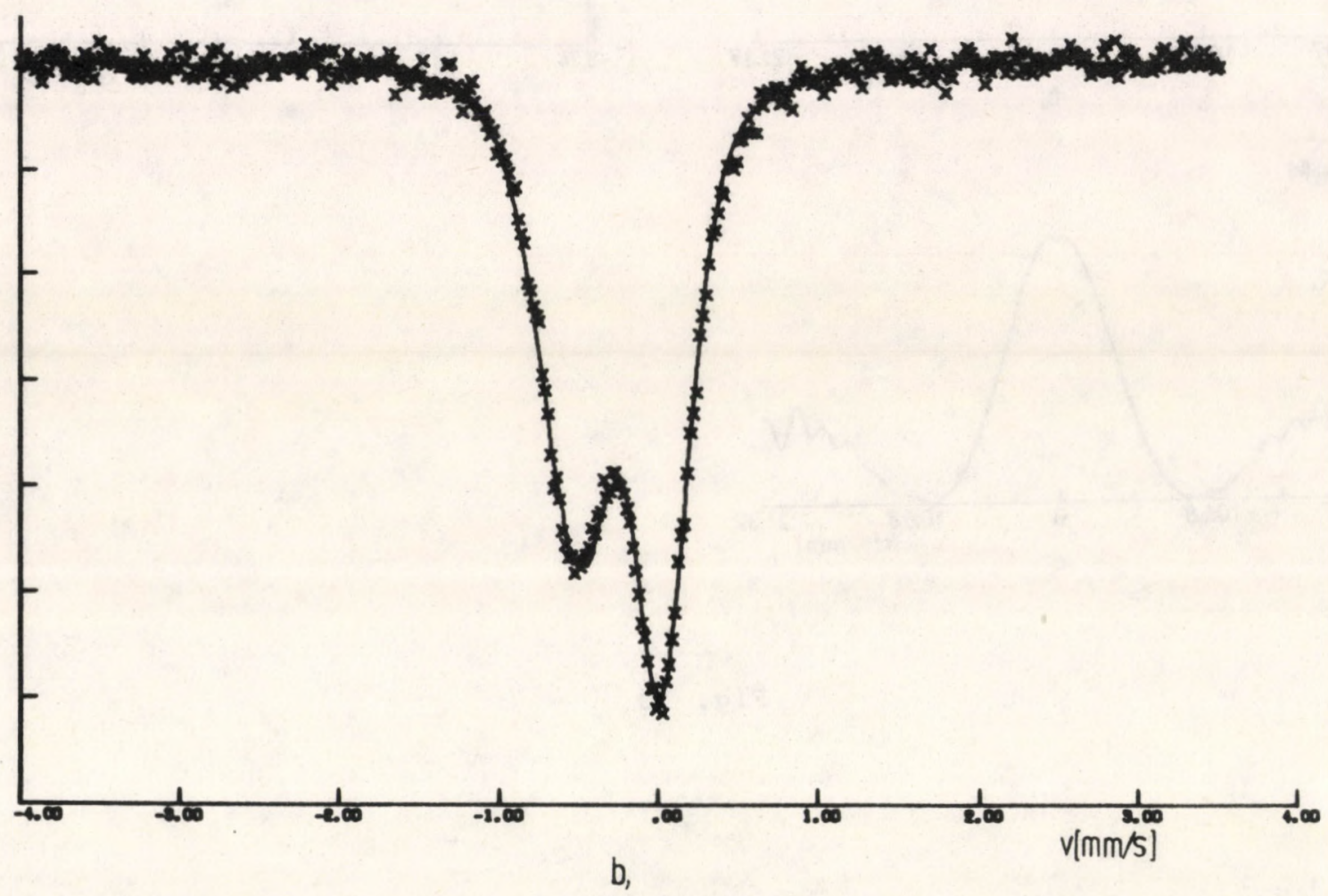

Fig. 11 


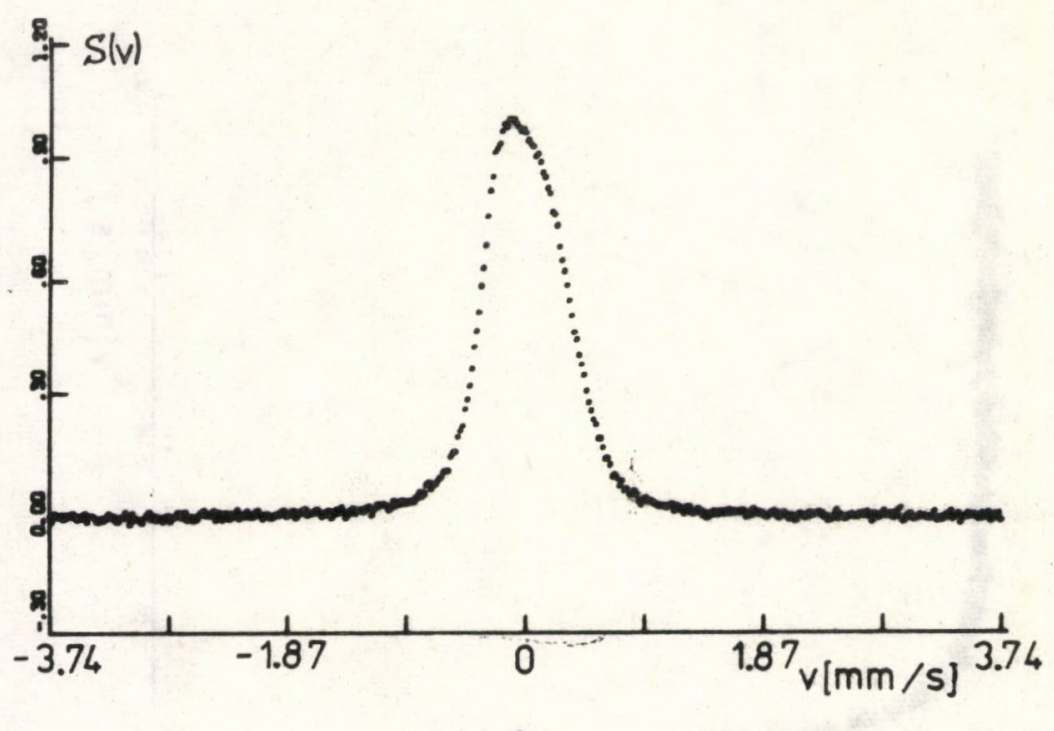

$a$;

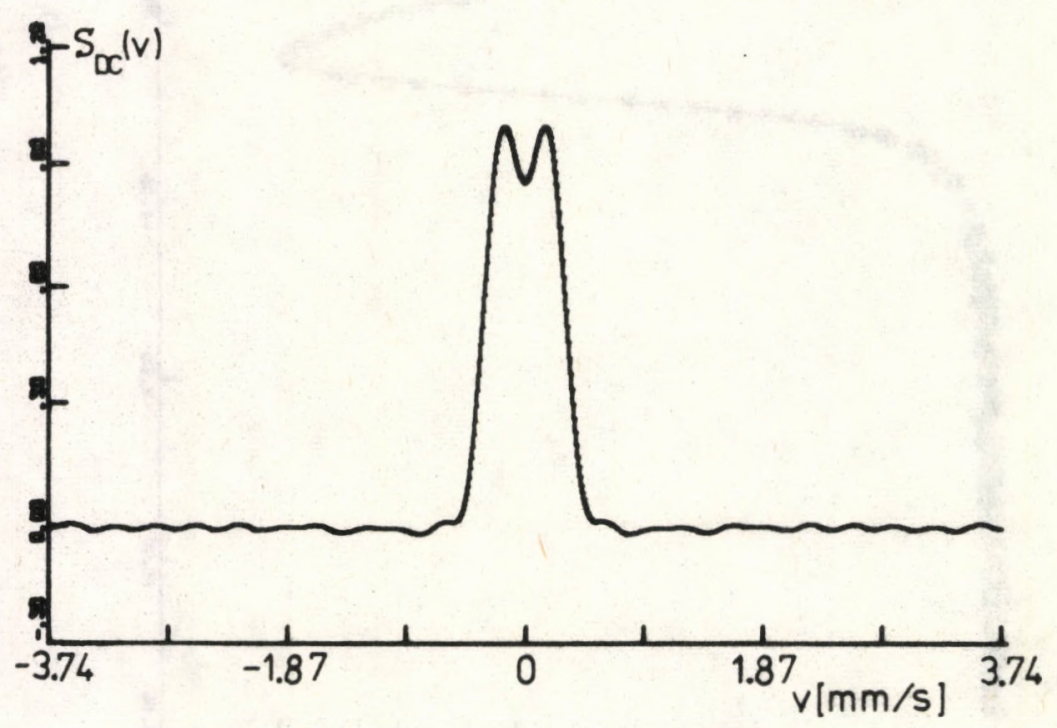

d,

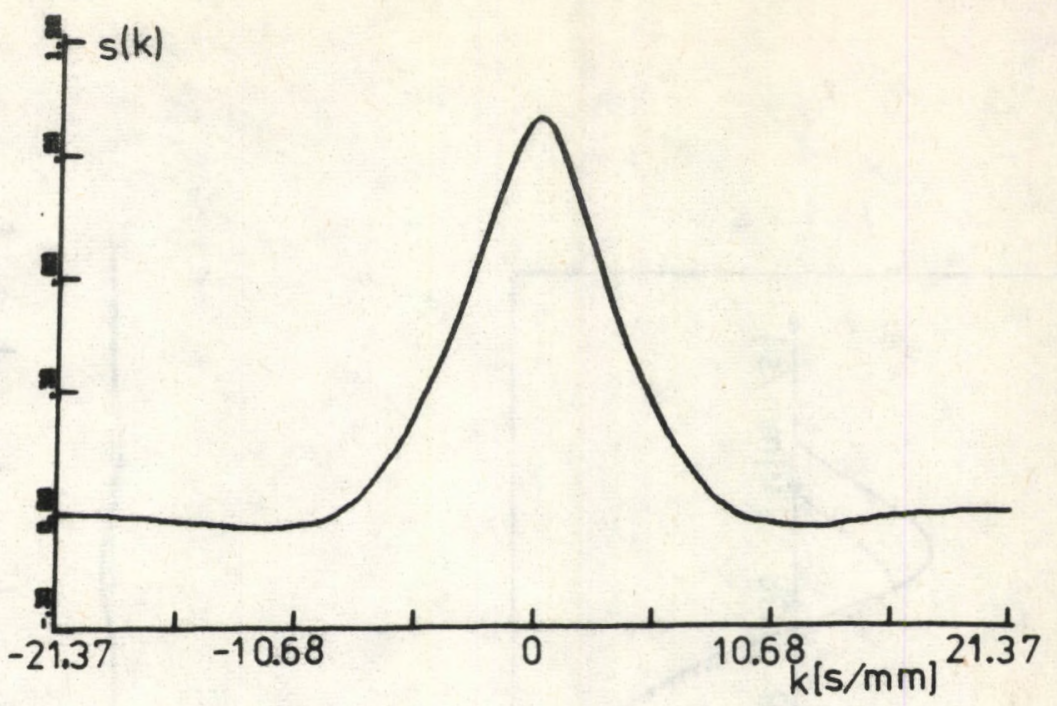

b)

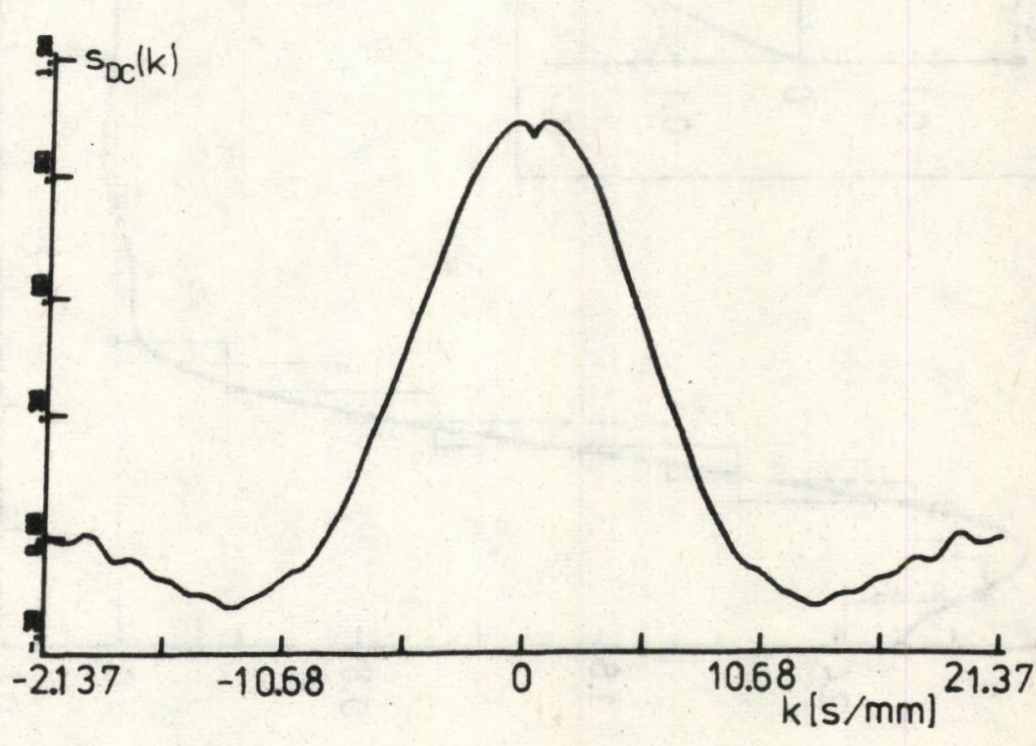

c, 

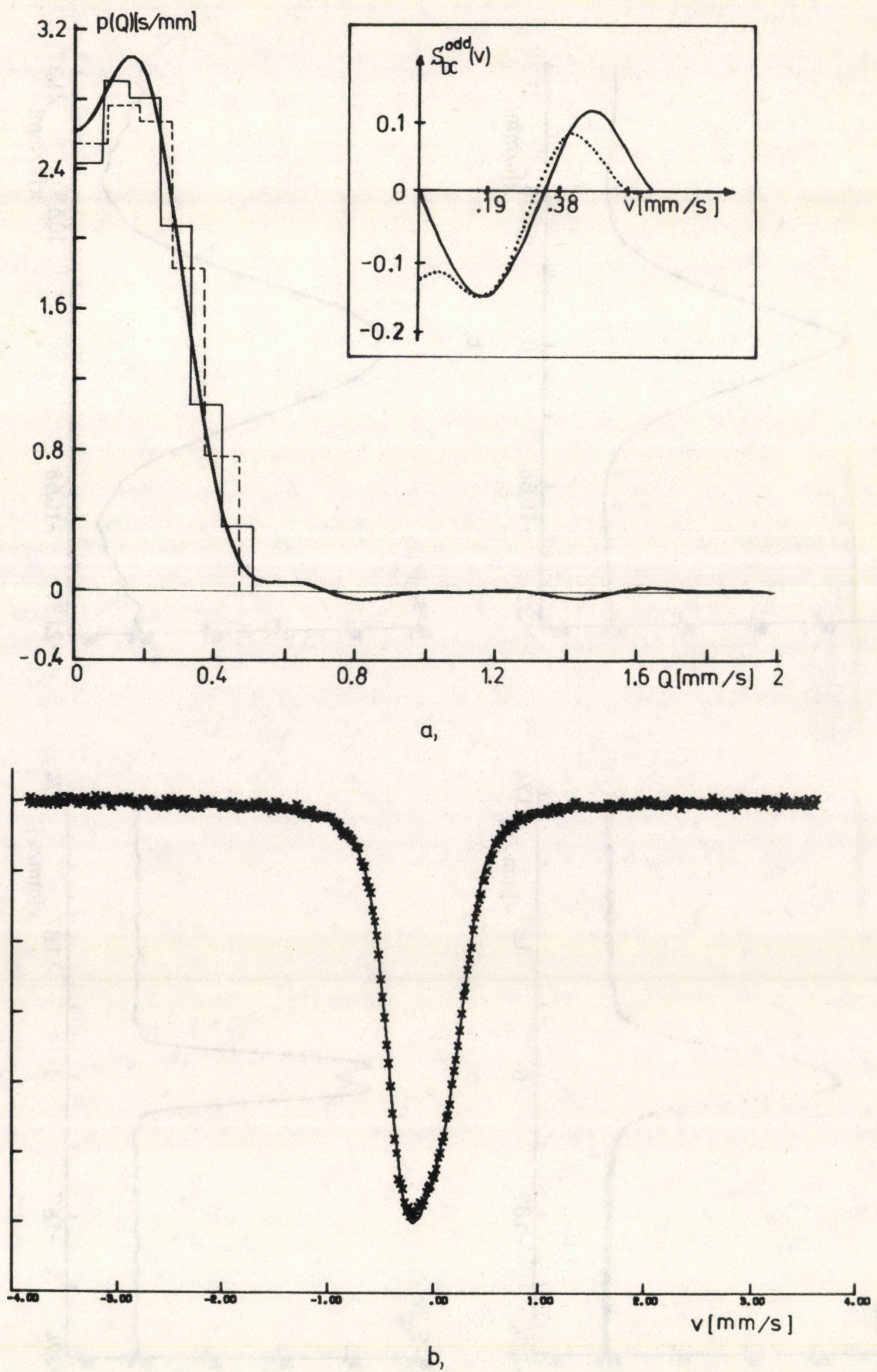

Fig. 13 

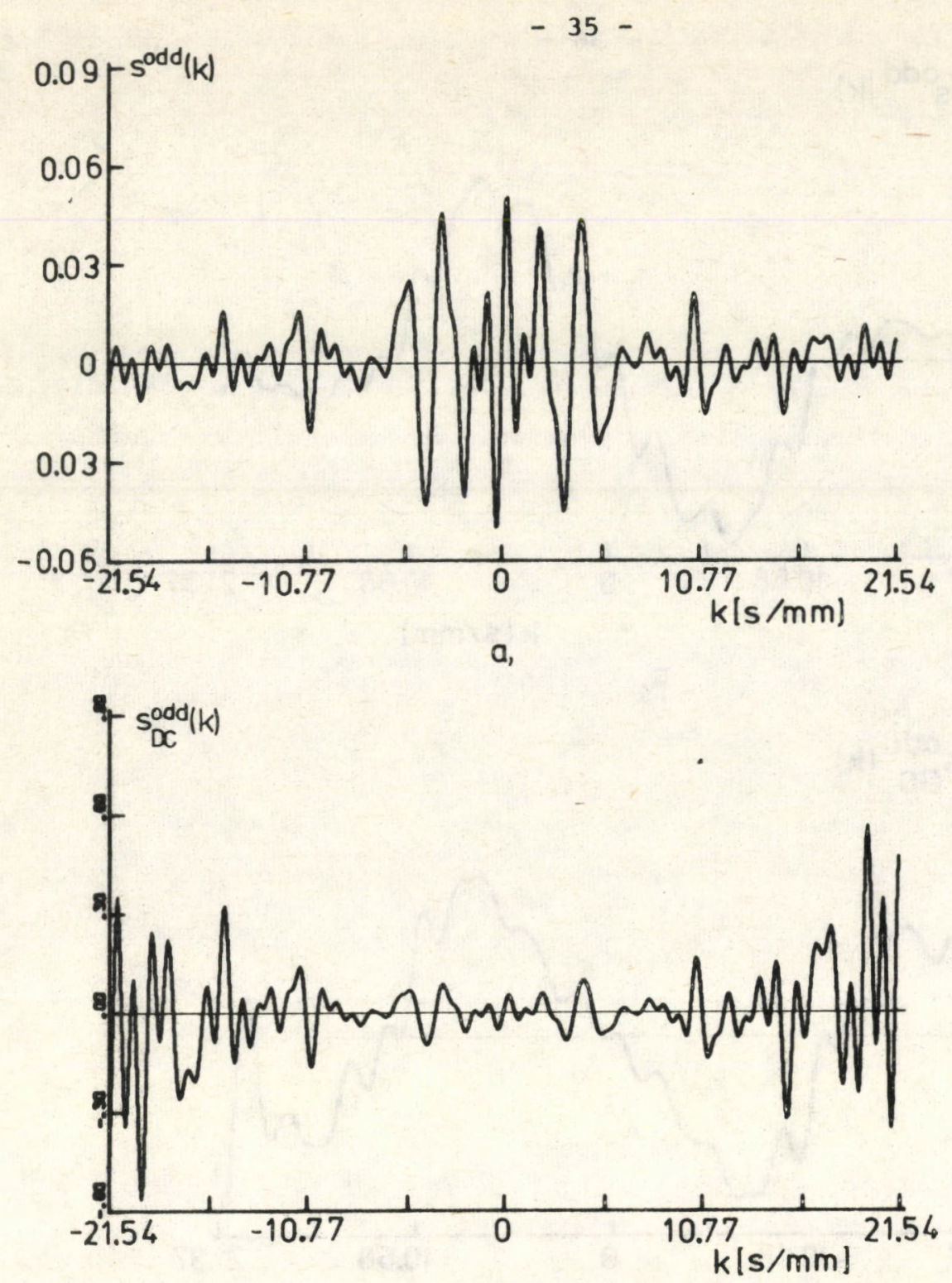

b,

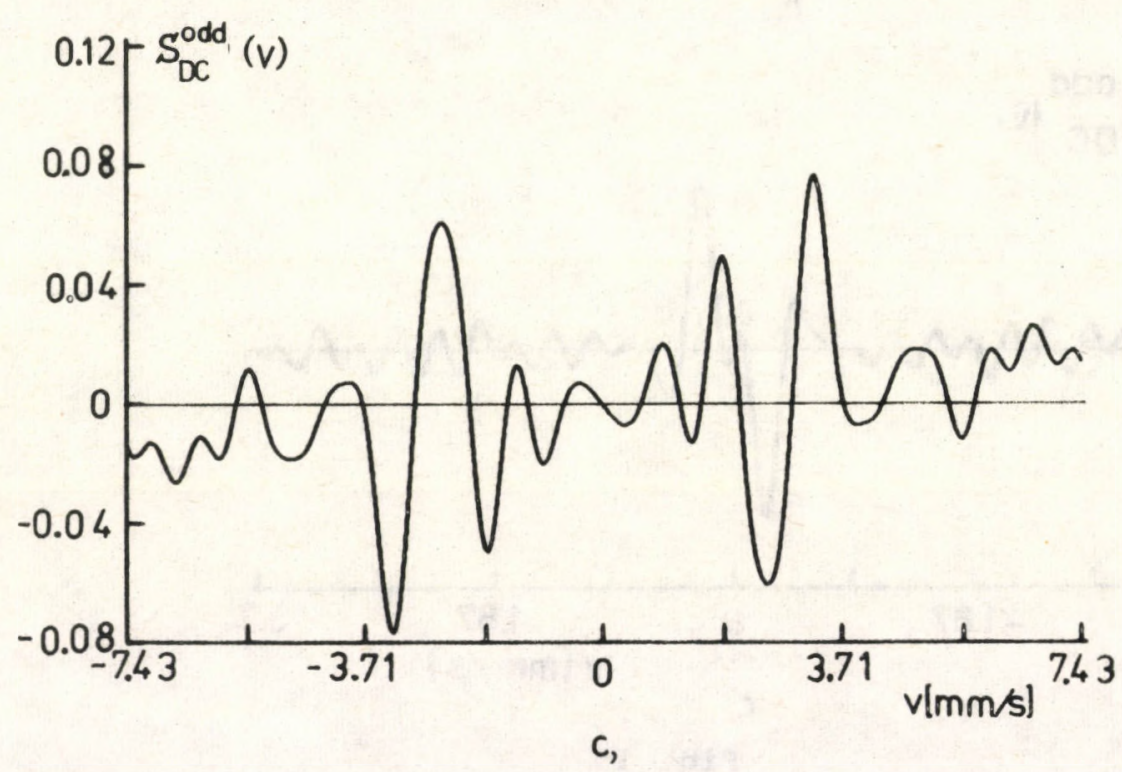

Fig. 14 


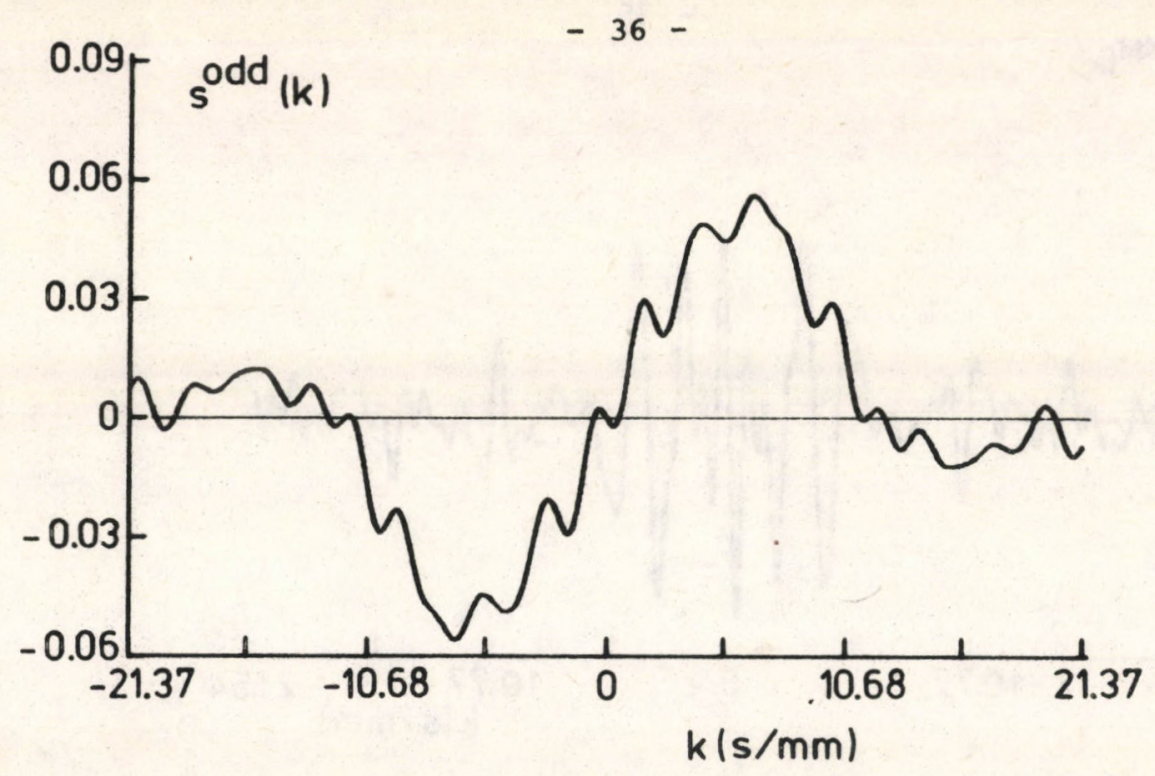

a,

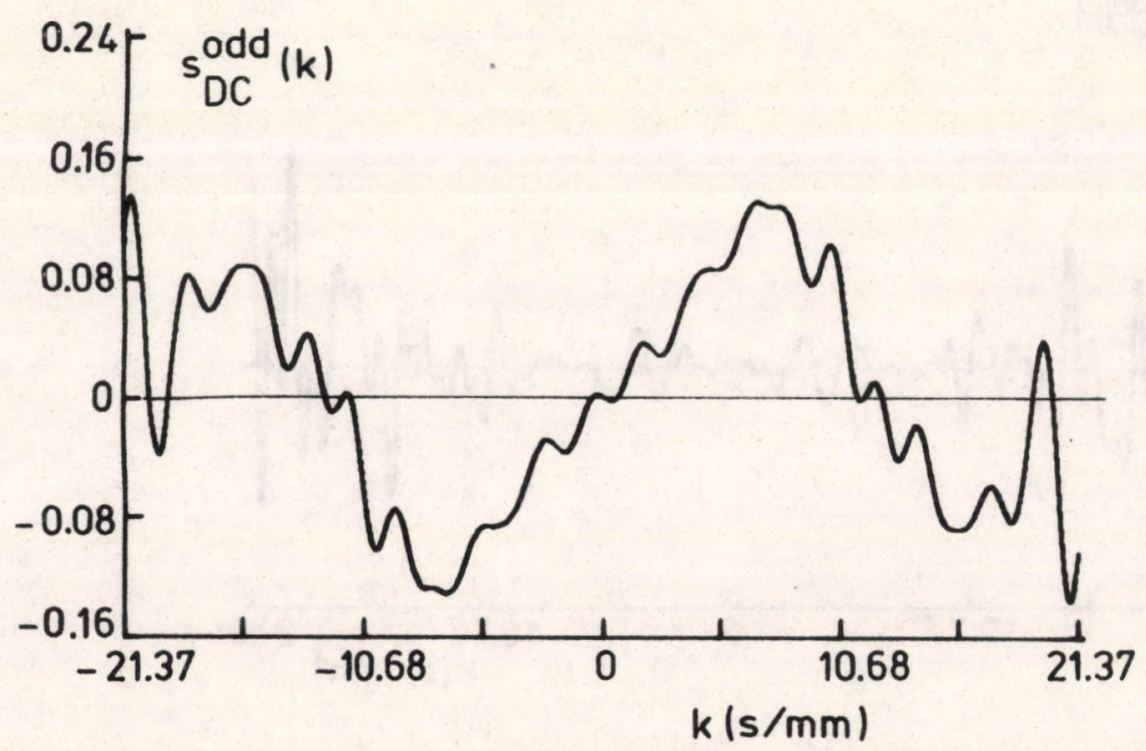

b.

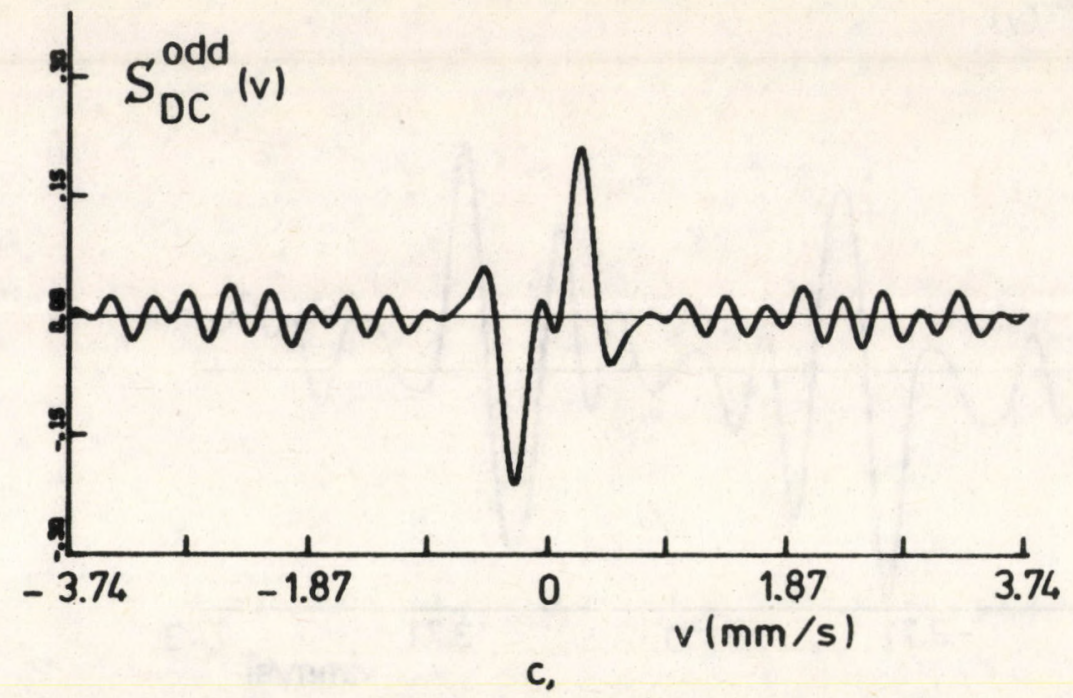

Fig. 15 


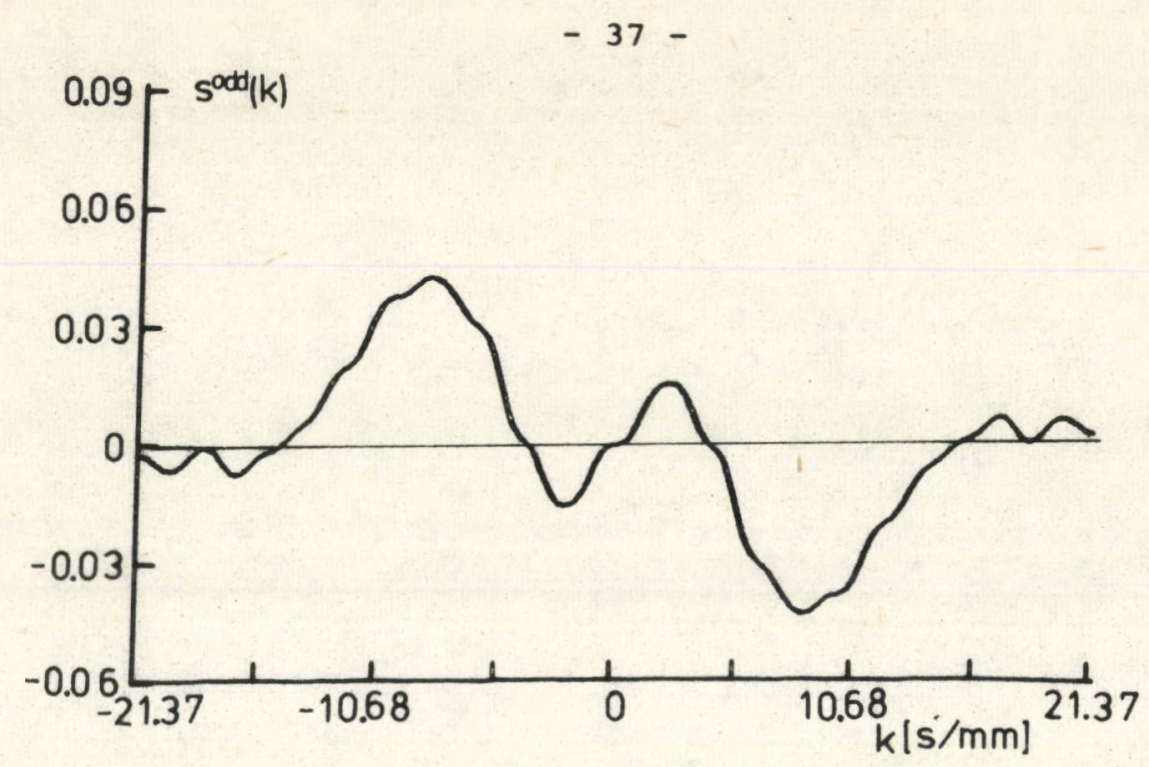

a,

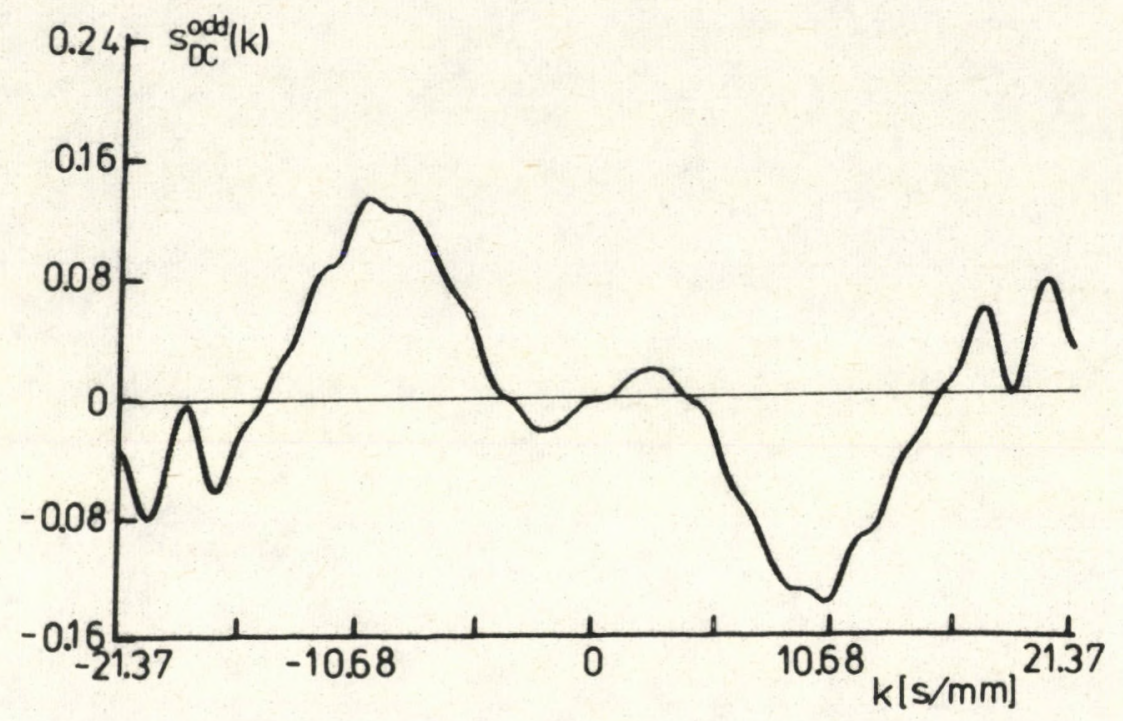

b,

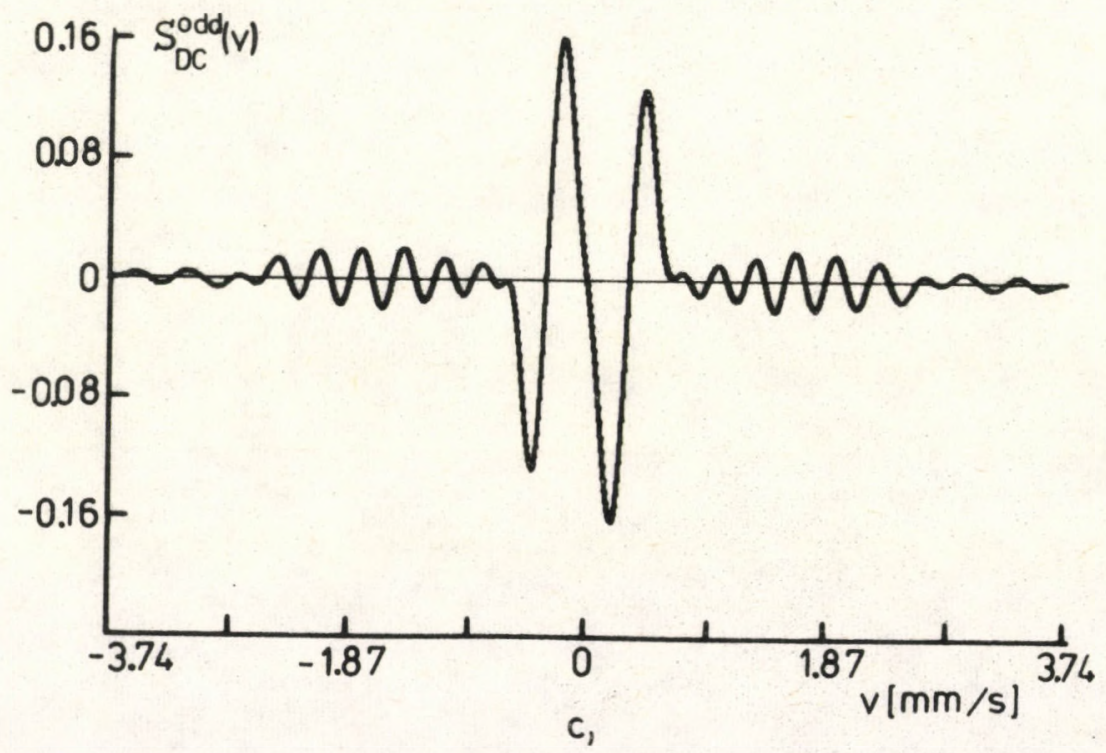

Fig. 16 






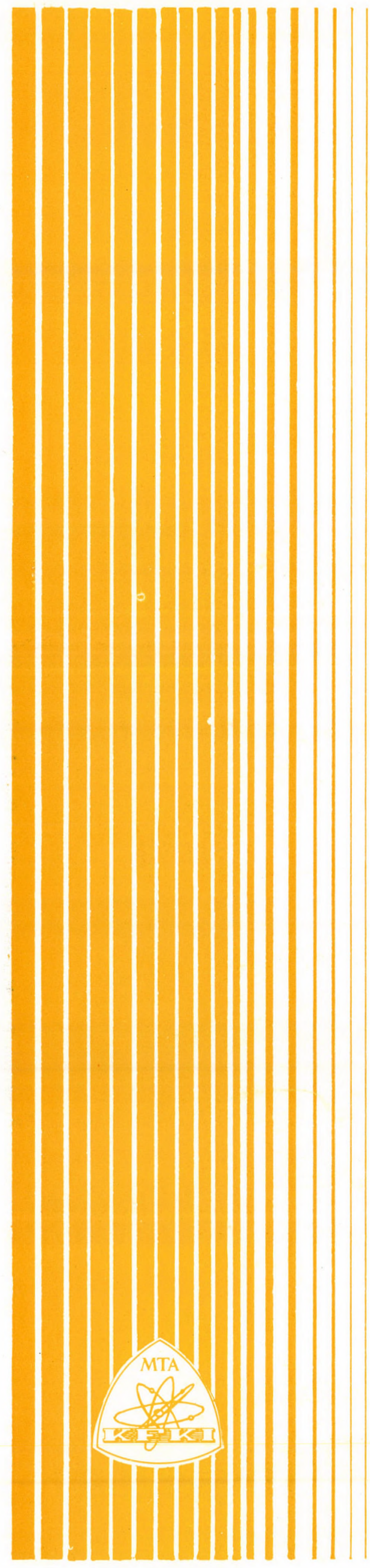

Kiadja a Központi Fizikai Kutató Intézet Felelõs kiadó: Kroó Norbert

Szakmai lektor: Kemény Tamás Nyelvi lektor: Kemény Tamás

Példányszám: 570 Törzsszám: 81-532

Készült a KFKI sokszorositó üzemẻben

Felelốs vezetõ: Nagy Károly

Budapest, 1981. szeptember hó 